OPEN ACCESS

Edited by:

Ashok Kumar,

University of Florida, USA

Reviewed by:

Raja S. Settivari,

The Dow Chemical Company, USA

Arianna Bellucci,

University of Brescia, Italy

${ }^{*}$ Correspondence:

Rona R. Ramsay

rrr@st-andrews.ac.uk

Massimo Valoti

massimo.valoti@unisi.it

Specialty section:

This article was submitted to

Neuropharmacology,

a section of the journal

Frontiers in Neuroscience

Received: 01 May 2016 Accepted: 02 August 2016

Published: 22 August 2016

Citation:

Ramsay RR, Majekova M, Medina M and Valoti M (2016) Key Targets for

Multi-Target Ligands Designed to Combat Neurodegeneration.

Front. Neurosci. 10:375.

doi: 10.3389/fnins.2016.00375

\section{Key Targets for Multi-Target Ligands Designed to Combat Neurodegeneration}

\author{
Rona R. Ramsay ${ }^{1 *}$, Magdalena Majekova ${ }^{2}$, Milagros Medina ${ }^{3}$ and Massimo Valoti ${ }^{4 *}$ \\ ${ }^{1}$ Biomedical Sciences Research Complex, University of St. Andrews, St. Andrews, UK, ${ }^{2}$ Department of Biochemical \\ Pharmacology, Institute of Experimental Pharmacology and Toxicology, Slovak Academy of Sciences, Bratislava, Slovakia, \\ ${ }^{3}$ Departamento de Bioquímica y Biología Molecular y Celular, Facultad de Ciencias and BIFI, Universidad de Zaragoza, \\ Zaragoza, Spain, ${ }^{4}$ Dipartimento di Scienze della Vita, Università degli Studi di Siena, Siena, Italy
}

\section{HIGHLIGHTS}

- Compounds that interact with multiple targets but minimally with the cytochrome P450 system (CYP) address the many factors leading to neurodegeneration.

- Acetyl- and Butyryl-cholineEsterases (AChE, BChE) and Monoamine Oxidases A/B (MAO A, MAO B) are targets for Multi-Target Designed Ligands (MTDL).

- ASS234 is an irreversible inhibitor of MAO A >MAO B and has micromolar potency against the cholinesterases.

- ASS234 is a poor CYP substrate in human liver, yielding the depropargylated metabolite.

- SMe1EC2, a stobadine derivative, showed high radical scavenging property, in vitro and in vivo giving protection in head trauma and diabetic damage of endothelium.

- Control of mitochondrial function and morphology by manipulating fission and fusion is emerging as a target area for therapeutic strategies to decrease the pathological outcome of neurodegenerative diseases.

Growing evidence supports the view that neurodegenerative diseases have multiple and common mechanisms in their aetiologies. These multifactorial aspects have changed the broadly common assumption that selective drugs are superior to "dirty drugs" for use in therapy. This drives the research in studies of novel compounds that might have multiple action mechanisms. In neurodegeneration, loss of neuronal signaling is a major cause of the symptoms, so preservation of neurotransmitters by inhibiting the breakdown enzymes is a first approach. Acetylcholinesterase (AChE) inhibitors are the drugs preferentially used in $A D$ and that one of these, rivastigmine, is licensed also for PD. Several studies have shown that monoamine oxidase (MAO) $B$, located mainly in glial cells, increases with age and is elevated in Alzheimer (AD) and Parkinson's Disease's (PD). Deprenyl, a MAO B inhibitor, significantly delays the initiation of levodopa treatment in PD patients. These indications underline that AChE and MAO are considered a necessary part of multi-target designed ligands (MTDL). However, both of these targets are simply symptomatic treatment so if new drugs are to prevent degeneration rather than compensate for loss of neurotransmitters, then oxidative stress and mitochondrial 
events must also be targeted. MAO inhibitors can protect neurons from apoptosis by mechanisms unrelated to enzyme inhibition. Understanding the involvement of MAO and other proteins in the induction and regulation of the apoptosis in mitochondria will aid progress toward strategies to prevent the loss of neurons. In general, the oxidative stress observed both in $P D$ and $A D$ indicate that antioxidant properties are a desirable part of MTDL molecules. After two or more properties are incorporated into one molecule, the passage from a lead compound to a therapeutic tool is strictly linked to its pharmacokinetic and toxicity. In this context the interaction of any new molecules with cytochrome P450 and other xenobiotic metabolic processes is a crucial point. The present review covers the biochemistry of enzymes targeted in the design of drugs against neurodegeneration and the cytochrome P450-dependent metabolism of MTDLs.

Keywords: multi target designed ligands, mitochondria, oxidative stress, monoamine oxidase, cytochrome P450, neurodegeneration

\section{INTRODUCTION}

Neurodegeneration is a complex process that can arise from many different defects or insults. In the last five years at least 80 reviews with "neurodegeneration" in the title have appeared, each covering different aspects of the processes involved. These include protein aggregation, mitochondrial movement, and function, dysregulation of microRNA, iron accumulation, inflammation, defects in proteins such as sirtuins or tau, dysregulation of protein trafficking or breakdown, and oxidative stress (Donmez, 2012; Gascon and Gao, 2012; Schipper, 2012; Sheng and Cai, 2012; Costanzo and Zurzolo, 2013; Butterfield et al., 2014; Moussaud et al., 2014; Rao et al., 2014; Wang X. et al., 2014; Witte et al., 2014; Goedert, 2015; Sankowski et al., 2015). With such complexity, it has proved difficult to identify biomarkers to quantify progression and targets to block to prevent the degeneration. The most obvious physiological symptoms are the loss of neurons in Alzheimer's Disease (AD) and Parkinson's Disease (PD) with the consequently lower neurotransmitter levels, and the formation of protein aggregates in all forms of neurodegeneration. These observations provided the primary targets to date, namely enzymes catalyzing neurotransmitter breakdown (cholinesterases, ChE; monoamine oxidases, MAO; catechol-O-methyltransferase, COMT), prevention of production of amyloid beta $(\mathrm{A} \beta)$ by beta-secretase, of protein aggregation, and of oxidative damage known to stress cells to the point of apoptosis (Guzior et al., 2015; Swomley and Butterfield, 2015). Intervention in the potentially damaging outcomes of oxidation stress either by means of upstream (prevention of free radical generation) or downstream (free radical scavenging) antioxidant pathways helps preserve neurons and slow neurodegeneration (Uttara et al., 2009).

Related to oxidative damage and because of their role in the regulation of apoptosis, mitochondria are a current active

Abbreviations: AD, Alzheimer's Disease; $\mathrm{AChE}$, acetylcholinesterase; $\mathrm{A} \beta$, amyloid beta; BChE, butyrylcholinesterase; MAO, monoamine oxidase; CYP, cytochrome P450; AIF, apoptosis inducing factor; MTDL, multi-target designed ligand; PD, Parkinson's Disease; ROS, Reactive Oxygen Species; CI Complex I, HLM, human liver mitochondria; RLM, rat liver mitochondria. area of investigation both for generation of reactive oxygen species (ROS) or inefficient energy production that limits defenses against ROS. Recent advances focus on mitochondrial movement, fusion, and fission and interactions with the cytosol (including specific proteins related to neurodegeneration such as the Bax/Bid family and sirtuins) (Eckert et al., 2012; Johri and Beal, 2012). Mitochondria play a central role in the oxidative metabolism of nutrients and ATP synthesis. They also contribute to intracellular second messenger homeostasis $\left(\mathrm{Ca}^{2+}\right.$ and $\left.\mathrm{ROS}\right)$, and are determinant for both cell survival and apoptotic cell coordination (Waagepetersen et al., 2003; Mandemakers et al., 2007; Nunnari and Suomalainen, 2012; Bernardi et al., 2015). Mitochondrial dysfunction is frequently proposed to be involved in neurodegenerative pathogenesis, including PD and AD (Mandemakers et al., 2007; Moreira et al., 2010; Correia et al., 2012a,b; Perier et al., 2012; Perier and Vila, 2012). With their high energy demands neurons are particularly dependent on mitochondrial ATP generation, and are thus intolerant of mitochondrial dysfunction (Lezi and Swerdlow, 2012). This makes the understanding of the mitochondrial mechanisms underlying these pathologies critical for designing more effective strategies to halt or delay disease progression (Correia et al., 2010a,b). An alternative strategy to preserving levels of neurotransmitters by inhibiting breakdown is the pharmacological stimulation of the post-synaptic receptors in the remaining neurons. Most receptors are G-protein coupled receptors (http://www.guidetopharmacology.org/), an area of fast recent progress with the determination of receptor structures, such as the muscarinic acetylcholine receptors (Thal et al., 2016), the availability of cloned receptors for pharmacology and compound screening (Katritch et al., 2013; Melancon et al., 2013), and new methods for assessing the complex function of the receptors (van Unen et al., 2015). Here too, multiple targets are attractive: for example, first-in-class dual M1/M4 agonists now in preclinical development (http://www. heptares.com/pipeline/). Antagonists to histamine receptors are also interesting to prevent the inflammation also thought to contribute to neurodegeneration (Vohora and Bhowmik, 2012; Walter and Stark, 2012). However, a meta-analysis of 
placebo-controlled trials for $\mathrm{H} 3$ receptor antagonists did not find significant effects on cognition (Kubo et al., 2015). Receptors will not be further mentioned in this article because we focus on intracellular targets.

It is apparent from the above outline that the primary causes of neurodegeneration are not easily defined, and will almost certainly be due to highly individual combinations of factors. This has led to the search for novel compounds that will interact with multiple targets, and have antioxidant properties as part of the desired pharmacologic profile. For the future there will be a need for various combinations of multi-target designed ligands (MTDL) to meet the needs of each individual combination of defects. In this article, we shall describe the background to in vitro assessment of compounds to combat neurodegeneration, considering the current targets either for symptomatic treatment (AChE and MAO) or to prevent or reverse deterioration (anti-oxidants or mitochondrial function), and giving examples of compounds from our own work conducted in collaborations facilitated by COST Action CM1103 "Structure-based drug design for diagnosis and treatment of neurological diseases: dissecting and modulating complex function in the monoaminergic systems of the brain."

Screening techniques highlight that many enzymes and receptors interact with a given chemical. This is clear in off-target data-mining (Nikolic et al., 2015; Hughes et al., 2016) and in high throughput screens (Sipes et al., 2013). In the latter project aimed at building a resource of biological pathways of toxicity for various types of chemicals, 976 compounds known as pharmaceuticals, food additives or pesticides were tested for inhibition or activation of enzymes and for binding to monoaminergic transporters and receptors. The most common sub-micromolar interactions were with the cytochrome P450 (CYP) family, transporters, the mitochondrial translocator (benzodiazepine-binding) protein, the dopamine and serotonin reuptake carriers, and the aminergic G-protein coupled receptors, and MAO was also in the top 20 most promiscuous proteins. These results indicate the promise of MTDL for cholinesterase (lower on that list) and MAOs or to include receptor agonism or antagonism into one molecule is not without the drawback of also finding off-target activity. In particular, any effect on the metabolic CYP enzymes must be carefully appraised.

After the identification of the target, be it receptor or enzyme, a variety of empirical and/or in silico studies are conducted in order to vary the structure to increase the pharmacological effects of the new compounds. However, good in vitro activity may not correspond to a therapeutic effect, unless the molecule also possesses high bioavailability and low toxicity. This means that the new compounds must have good pharmacokinetic properties. The investigation on absorption, distribution, metabolism and excretion properties and toxicological profiling (ADME/Tox) have become an essential step in early drug discovery that has demonstrated a high impact on the successful progression of drug candidates. Growing knowledge of the key roles that pharmacokinetics and drug metabolism play as determinants of in vivo drug action, has led many researchers, drug companies and regulatory agencies to include examination of pharmacokinetics and drug metabolism properties as part of their process in the selection of drug candidates. In this context, the role of the CYP isoenzymes is outlined, since it represents a major source of variability toward pharmacokinetics and pharmacological responses in this phase.

In this review we consider the biochemistry of some of the key pharmacological targets of MTDL, giving selected examples from our own expertise. The traditional key targets in Alzheimer's Disease (AD), the ChEs and MAOs, are described first, then the new and diverse potential targets in mitochondrial function for cell survival, followed by an example of targeting the oxidative stress that is seen in a variety of degenerative conditions. Lastly in this overview of metabolic aspects of drug design, the action of the CYP isoezymes, important for effectiveness of all drugs in vivo, on MTDL is described.

\section{ADDRESSING THE PATHOLOGY OF NEURODEGENERATION: THE TARGETS CONSIDERED HERE}

Four of the five drugs ever approved to treat symptoms of memory loss and confusion in $\mathrm{AD}$ patients are cholinesterase inhibitors. The cholinergic hypothesis of $\mathrm{AD}$ posits that the cognitive and behavioral dysfunctions of $\mathrm{AD}$ result from deficits in acetylcholine neurotransmission. These early symptoms can be ameliorated by inhibiting the cholinesterases to prolong the presence of acetylcholine in the synapse. However, cholinesterase activities have also been reported correlate with the density of amyloid plaque deposition in the AD brain (Arendt et al., 1992). The mechanism by which AChE and to a lesser extent BChE facilitate plaque deposition is still being investigated (Hou et al., 2014).

The other catabolic enzyme that is inhibited to maintain decreasing neurotransmission is MAO, located on the cytosolic face of the mitochondrial outer membrane where it is attached by a single membrane-spanning helix. To be metabolized by $\mathrm{MAO}$, monoamine neurotransmitters must be taken up into the cells. The two forms, MAO A and MAO B, are co-located in liver mitochondria, but otherwise have very different expression patterns. MAO A is the major form in the intestine and placenta, MAO B in platelets. In the brain, MAO B is expressed in the glia and in serotonergic neurons, whereas MAO A predominates in all other neurons.

Mitochondria produce the majority of energy in all type of cells but particularly in neurons where the energy demand for neurotransmission is high. Deficits in mitochondrial function (i.e., increased oxidative stress, decreased efficiency of the respiratory chain, apoptosis dysfunctions, deregulation of fusion and fission processes) have been found in all neurodegenerative conditions. Understanding the mechanisms underlying these pathologies is critical to designing more effective strategies to halt or delay disease progression (Correia et al., 2010a, 2012a). Each of the mitochondrial functions is closely related to the others and alteration in any of them might develop neurodegeneration, making difficult to discriminate which changes are more critical (Haddad and Nakamura, 2015). Abnormal morphology, altered 
dynamics, and biochemical dysfunction of mitochondria are usually observed, being often systemic rather than brain-limited (Lezi and Swerdlow, 2012).

Mitochondrial respiratory capacity and efficient ATP production are vital for neuronal survival. In most neurodegenerative conditions mutations accumulate in mitochondrial DNA (encoding 13 proteins essential for respiratory chain function), the enzymatic activity of respiratory chain enzymes is altered and oxidative stress usually increases (Goldberg et al., 2002). Such dysfunctions arise not only as consequence of mutations in mitochondrial DNA but can also be due to mutations in nuclear DNA encoding for proteins either imported to or interacting with the mitochondria. Changes in the mitochondrial membrane potential and the increased reactive oxygen species (ROS) associated with electron transport chain dysfunction have been strongly linked to reduced cell viability (Bird et al., 2014). Although ROS formation is a natural by-product of mitochondrial respiration, overproduction is indicative of cell stress (Murphy, 2009). Antioxidant therapy has therefore long been sought to combat aging as well as neurodegeneration.

Antioxidant compounds can either react with radicals to prevent damage to biological molecules (proteins, lipids or DNA) or can complex metal ions to decrease generation of ROS. Iron ions are the well-established target in $\mathrm{AD}$, playing a key catalytic role in the Fenton reaction (reviewed in Unzeta et al., 2016). Knock out studies have established that loss of Amyloid Precursor Protein (APP) or tau (both AD-linked proteins) results in iron accumulation in the brain. Iron is bound to ferritin, a protein that increases with age and in $\mathrm{AD}$ (Bartzokis and Tishler, 2000). Iron is found also in plaques (Meadowcroft et al., 2009). Iron-chelation capability is part of the action spectrum of rasagiline used for treatment of PD (Weinreb et al., 2016) and a highly desirable addition to future MTDL compounds for prevention of neurodegeneration.

Lastly, decreasing the generation of aberrant proteins, preventing their aggregation, and blocking down-stream events are developing targets. The prevention of production of amyloid beta $(A \beta)$ by inhibition of the beta-secretases already has led to candidate small molecule compounds in clinical trials (Yan and Vassar, 2014; Yan et al., 2016). The acceleration of $A \beta$ aggregation by the peripheral site of $\mathrm{AChE}$ has long been recognized (Inestrosa et al., 1996; Reyes et al., 1997) and is an important component of effective AChE inhibitors designed to combat AD (Bartolini et al., 2003; Anand and Singh, 2013; Bolea et al., 2013; Bautista-Aguilera et al., 2014a; Hebda et al., 2016). Deleterious intracellular effects of $A \beta$ are also recognized, such as the consequences of $A \beta$ binding to a $17-\beta$-hydroxysteroid dehydrogenase known as Amyloid Binding Alcohol Dehydrogenase (ABAD), a tetrameric mitochondrial enzyme that catalyzes the oxidation of steroids. $\mathrm{ABAD}$ is decreased in $\mathrm{AD}$ (Lustbader et al., 2004) and missense mutations in its gene (HSD17B10) result in alteration of mitochondria morphology and neurodegeneration in infancy (Yang et al., 2014). The $A B A D-A \beta$ interaction is associated with upregulation of endophilin, a protein important for membraneshaping in processes such as synaptic vesicle formation which might contribute to neuronal sensitivity to $\mathrm{ABAD}-\mathrm{A} \beta$ complex formation inside neuronal mitochondria (Borger et al., 2013). Drug discovery to prevent the $\mathrm{ABAD}-\mathrm{A} \beta$ interaction, begun with brain-permeant peptides (Borger et al., 2013), is now moving to small molecules (Valaasani et al., 2014; Benek et al., 2015; Hroch et al., 2015) that will provide information for future incorporation into multi-target compounds.

The aim of MTDL design is to combine features that can interact with two or more of the desired targets (Csermely et al., 2005; Geldenhuys et al., 2011; Hughes et al., 2016). This expands the biological screening required at the early stages for hit discovery and lead optimization. With structures of most targets available, in silico screening is a useful tool for examining large chemical databases (Hughes et al., 2016; Nikolic et al., 2016). Combining known drugs for each target into one molecule has also produced promising compounds by incorporating elements of proven inhibitors for each target into new multi-potent molecules (Bolognesi et al., 2007; Piazzi et al., 2008; Zhu et al., 2009; Kupershmidt et al., 2012; Luo et al., 2013; Sun et al., 2014; Bautista-Aguilera et al., 2014b; Wang L. et al., 2014; Pisani et al., 2016; Weichert et al., 2016; Xie et al., 2016). One example that progressed to clinical trials against $\mathrm{AD}$ is ladostigil, designed to inhibit MAOs and ChEs but also incorporating potent antiapoptotic and neuroprotective activities (Weinreb et al., 2012; Youdim, 2013). The next sections in this review will consider other examples of MTDL in the context of some of these targets of interest for $\mathrm{AD}$ drugs.

\section{NEUROTRANSMITTER DEGRADING ENZYMES \\ Enzyme Inhibitors-Pharmacological Characterization}

The development of novel drugs that target enzymes requires an understanding of enzyme mechanism and is deeply informed by detailed knowledge of the protein structure. Understanding how enzymes (or indeed receptors) work is vital for medicinal chemists aiming to design new drugs (Walsh, 2013). In the very first stage of evaluation of new compounds in a biological system, the medicinal chemistry shortcut of $\mathrm{IC}_{50}$ measurement is an invaluable tool for comparisons of series of derivatives on a given scaffold and provides useful information for determining a hit or for choice of a lead compound. It is a measurement that can be used for both simple and complex biological systems but it is important to recognize that the meaning of $\mathrm{IC}_{50}$ (as opposed to its definition as $50 \%$ inhibition of a measured parameter) changes according to the system and the assay conditions. In the context of measurement of a single enzyme activity, $\mathrm{IC}_{50}$ is not affinity for a target but simply the concentration of the compound that inhibits the activity by $50 \%$ under the specific conditions used. For more informative data on enzyme reversible inhibitors, the $\mathrm{K}_{\mathrm{i}}$ (the inhibition constant independent of the substrate concentration used) and the mechanism of inhibition should be determined. For irreversible inhibitors, the rate of inactivation and the concentration dependence are needed (McDonald and Tipton, 2012). It should be recognized that $\mathrm{IC}_{50}$ values for 
reversible and irreversible inhibitors are not directly comparable because of the time element. The initial reversible binding of an inactivating inhibitor can only be compared with reversible inhibitors (or indeed binding constants from docking) if initial rates are measured in an assay where the enzyme is added last to a mixture of substrate and inhibitor.

When comparing alternate targets, care is needed to use conditions for each target that will allow comparison. Selective inhibition of MAO A and MAO B is often desired, but they have different $K_{M}$ values for their common substrates (the concentration of substrate required to give half the maximum velocity), so are saturated to different degrees at any one concentration. For example, purified human MAO A activity reaches $50 \%$ of its maximum at $0.15 \mathrm{mM}$ kynuramine, whereas MAO B reaches $50 \%$ of maximum rate with only $0.08 \mathrm{mM}$ kynuramine. With reversible inhibitors,

$\mathrm{E}+\mathrm{I} \leftrightarrow \mathrm{EI}$ but during steady state measurement, when $\mathrm{E}+\mathrm{S}$ $\leftrightarrow \mathrm{ES} \rightarrow \mathrm{E}+\mathrm{P}$, the concentration of free enzyme (E) available to bind inhibitor is not the total enzyme added but rather a fraction of the total that depends on the substrate concentration used and the relative values of the rate constants. In the steady-state where ES is constant, MAO A assayed with $0.1 \mathrm{mM}$ kynuramine has $60 \%$ of free enzyme but MAO B has only $44 \%$ available for inhibitor binding. For an inhibitor of both with the same $\mathrm{K}_{\mathrm{i}}$ of $0.01 \mathrm{mM}$, the $\mathrm{IC}_{50}$ would be measured as $17 \mu \mathrm{M}$ for MAO A but $22.5 \mu \mathrm{M}$ for MAO B despite the fact that the inhibitor bound equally well to both enzymes. Simply using an assay with fixed substrate concentration without taking into account the different $\mathrm{K}_{\mathrm{M}}$ values would therefore introduce a $30 \%$ bias to the selectivity.

The mechanism of the enzyme can also influence $\mathrm{IC}_{50}$ values. This is seen in the kinetic analysis of MAO B where it is clear that there are two forms of the enzyme that can bind the ligand (substrate or inhibitor), namely, the oxidized or the reduced forms, and that these two forms bind ligands with different affinities. Since different substrates give different proportions of these forms during steady-state catalysis, different Ki values for an inhibitor can be obtained from different substrates. Overall, care must be exercised in choice of substrate and of assay conditions to obtain reliable $\mathrm{IC}_{50}$ values, but only kinetic constants can be considered meaningful (McDonald et al., 2010; Ramsay et al., 2011). Slow and tight binding inhibitors also require special analysis (Morrison, 1969).

For irreversible inhibition, a time course of the development of the inactive enzyme is essential. The best compounds for specific irreversible inhibition in vivo are mechanism-based inhibitors, making use of the catalytic specificity of the target itself. However, sometimes even mechanism-based activation to a reactive product can be catalyzed by more than one enzyme, as seen for the MAO inhibitor tranylcypromine that irreversibly modifies the flavin in MAO after single electron oxidation (Silverman, 1983; Bonivento et al., 2010). Tranylcypromine was recently found to modify also the flavin in the epigenetic histone demethylase enzyme LSD1 (Schmidt and McCafferty, 2007; Binda et al., 2010). For medicinal chemistry screening, irreversible inhibition can be detected as a decrease in the $\mathrm{IC}_{50}$ value after $30 \mathrm{~min}$ preincubation compared to no preincubation. For example, for MAO B the IC50 for tranylcypromine without preincubation is $4 \mu \mathrm{M}$ but if preincubated with the enzyme for 30 min before substrate is added, the $\mathrm{IC}_{50}$ is $0.074 \mu \mathrm{M}$ (Malcomson et al., 2015). Proper characterization of mechanism-based inactivation requires measurement of the rate of production of inactive enzyme over time with several inhibitor concentrations to obtain $\mathrm{K}_{\mathrm{I}}$ and $\mathrm{k}_{\text {inact }}$ (Kitz and Wilson, 1962).

Catalysis consists of both binding and kinetics steps. Theoretical screening measuring the sum of the optimal interactions between a compound and a target addresses only binding (and that with limitations depending on the restrictions placed on molecular dynamics). As a result, enzyme $\mathrm{IC}_{50}$ values are frequently not in accord with computed binding constants. Although $\mathrm{K}_{\mathrm{i}}$ and $\mathrm{K}_{\mathrm{D}}$ can be numerically the same if measurements are made in a simple Michaelis-Menten system, they never have the same meaning. Nonetheless, theoretical screening is a useful tool, particularly for large compound libraries and to facilitate repurposing of existing drugs used for other clinical targets (Hughes et al., 2016; Nikolic et al., 2016).

\section{Cholinesterases (AchE, BchE) AChE/BChE Location, Structure, Activity, Redundancy}

AChE is located at neuromuscular junctions and in the central nervous system on the outside of the post-synaptic cell membranes, mainly in a tetrameric form. A Ser-His-Glu catalytic triad in the active site catalyzes the hydrolysis, and anionic and hydrophobic groups in the peripheral anionic site (PAS) contribute to binding a wide range of chemical structures (Figure 1). The drug, donepezil, spans both sites with aromatic stacking contributing to the nanomolar binding affinity, as shown in the crystal structure of the human AChE (Cheung et al., 2012). The PAS has a function in allosteric modulation of AChE activity and in increasing amyloid (Inestrosa et al., 2008; Hou et al., 2014).

BChE may also have a role in amyloid plaque formation (Darvesh et al., 2012). It is found mainly in plasma as a soluble monomer secreted by glial cells (Greig et al., 2002). Although the two enzymes share $65 \%$ homology and a similar hydrophobic active site structure, they have different specificities in part due to two aromatic residues (Phe295 and Phe297) that constrict the 20 Å long gorge in AChE (Greig et al., 2002; Nicolet et al., 2003). The $K_{M}$ values and turnover numbers with acetylcholine are 0.1 $\mathrm{mM}$ and $6500 \mathrm{~s}^{-1}$ for AChE and $0.15 \mathrm{mM}$ and $1433 \mathrm{~s}^{-1}$ for BChE (http://www.brenda-enzymes.org). In the normal brain where AChE is localize on the post synaptic membrane it was estimated that $90 \%$ of acetylcholine hydrolysis is catalyzed by AChE (Greig et al., 2002). However, BChE is plentiful and secreted by the glial cells so that if AChE is inhibited or is defective as in AChE-knockout mice, the hydrolysis can be catalyzed by BChE (Mesulam et al., 2002). Thus, in current efforts to design multitarget drugs, reversible inhibition of both $\mathrm{AChE}$ and $\mathrm{BChE}$ is considered desirable.

\section{Cholinesterase Assay and Inhibitors}

Both AChE and BChE can be assayed using acetylthiocholine, but butyrylthiocholine is selective for BChE. The enzymes hydrolyse acetylthiocholine to acetate and thiocholine. Thiocholine reacts with Ellman's reagent (DTNB) to form a mixed dithiol, 


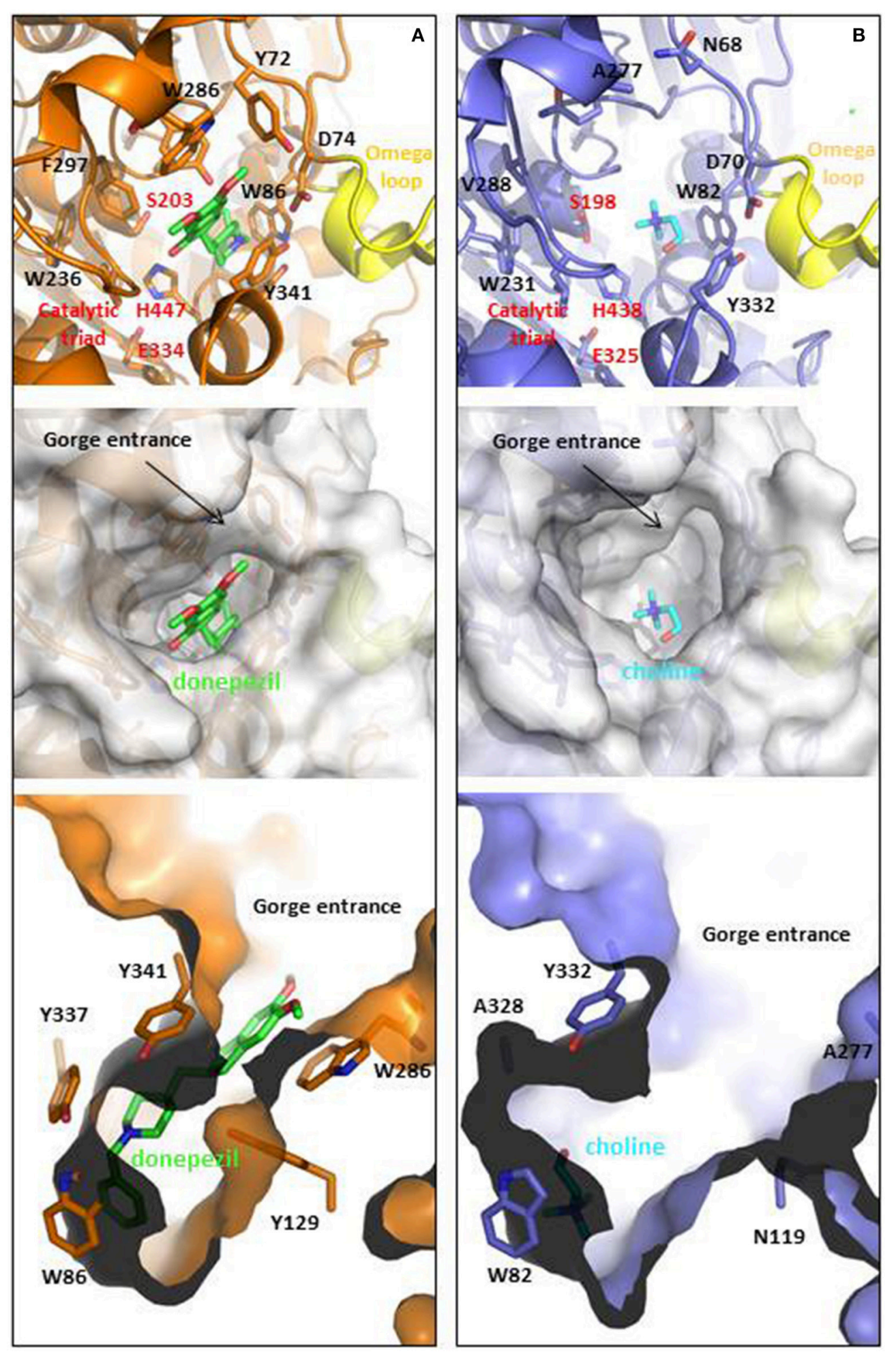

FIGURE 1 | Ligand binding cavities of (A) AChE and (B) BChE. AChE (shown in orange) is in complex with donepezil (shown in CPK colored sticks with carbons in green, PDB ID: 4EY7), while BChE (shown metal blue) is in complex with choline (shown in CPK colored sticks with carbons in light blue, PDB ID: 1POM). The top panels show the cartoon representations with detail in sticks of relevant residues involved at the gorge entrances, the PAS regions or the catalytic triads (labeled in red), as well as the omega loops colored in yellow. Middle and lower panels show top and lateral views of the ligand binding cavities. The entrance loops are highlighted in pink and yellow respectively. PDB files were obtained from the protein databank and figures were produced using the PyMol software (PyMOL, http://www.pymol.org). 
liberating 5-thio-2-nitrobenzoate that absorbs at $412 \mathrm{~nm}$. The molar absorption coefficient is $14,150 \mathrm{M}^{-1} \mathrm{~cm}^{-1}$; (Riddles et al., 1979) but it can vary slightly with salt concentration, $\mathrm{pH}$, and temperature (Ellman et al., 1961; Eyer et al., 2003). The $\mathrm{K}_{\mathrm{M}}$ for acetylthiocholine $(0.025-0.05 \mathrm{mM})$ is similar for both enzymes although the rate with $\mathrm{BChE}$ is slower.

Common drugs inhibiting AChE and BChE are donepezil and tacrine (see Table 1) (Camps et al., 2008; Esteban et al., 2014; Wang L. et al., 2014). Carbamates are also reversible inhibitors (e.g., rivastigmine), coumarins, and several natural compounds have also been investigated. Harmine, an endogenous compound from the breakdown of tryptophan is also an inhibitor (He et al., 2015). In the last 5 years most inhibitor development has focused on maintaining a relatively equal inhibitory activity against AChE and $\mathrm{BChE}$ with $\mathrm{IC}_{50}$ values below $\mu$ molar concentrations in a compound that also acts on other targets such as MAO (see below), antioxidant, metal chelation, and preventing protein aggregation (for reviews see: León et al., 2013; Swomley and Butterfield, 2015). Many groups have synthesized and tested a variety of combinations. Here, we consider in detail ASS234, an example from our own work. ASS234 (Table 1) with potency similar to tacrine is almost equipotent on human AChE and BChE. ASS234 also has antioxidant properties, inhibits $A \beta$ aggregation, and decreases $A \beta$-induced apoptosis in cellular studies (Bolea et al., 2013).

The discovery of compounds that combine cholinesterase inhibition with binding to other targets of interest for $\mathrm{AD}$ is also underway. For example, the serotonin receptor, $5-\mathrm{HT}_{4}$, has been linked to memory deficits (Cho and Hu, 2007; Lezoualc'h, 2007; Russo et al., 2009). Stimulation causes release of ACh and increases dopamine, serotonin, and $\gamma$-aminobutyric acid (GABA) release, and thus could act synergistically with $\mathrm{ChE}$ and MAO inhibition. $5-\mathrm{HT}_{4}$ stimulation also increases the safer non-amyloidogenic pathway for APP cleavage (Cochet et al., 2013). Agonists or partial agonists have been designed and the first MTDLs with cholinesterase and receptor binding have been designed (Lecoutey et al., 2014; Rochais et al., 2015).

\section{Monoamine Oxidases (MAO A, MAO B)}

Neurotransmitter levels influence brain activity and preventing neurotransmitter breakdown has an anti-depressant effect. The monoamines are catabolized by MAO and COMT, inhibitors for which are useful in PD (Talati et al., 2009). Mice treated with MAOI showed significantly higher noradrenaline and serotonin levels in brain and significantly lower metabolites (including DOPAC from dopamine) (Lum and Stahl, 2012). Higher monoamine levels as a result of MAOI are also seen in rats in micro-dialysis experiments (Bazzu et al., 2013; Bolea et al., 2014), and in humans are observed as serotonin toxicity in patients given non-selective MAOI on top of serotonin reuptake inhibitors (SSRIs) (Gillman, 2011). Changes in monoamine levels also have downstream effects on expression and function of receptors and other proteins (Finberg, 2014).

TABLE 1 | AChE and MAO inhibitors and the inhibitory activity of MTDL.

\begin{tabular}{|c|c|c|c|c|c|c|}
\hline Structure & Compound & AChE $(\mu \mathrm{M})$ & BChE ( $\mu$ M) & MAO A (nM) & MAO B (nM) & References \\
\hline & Donepezil & $\begin{array}{l}0.012^{1} \\
0.011^{2}\end{array}$ & $\begin{array}{l}7.3^{1} \\
6.22^{2}\end{array}$ & $\begin{array}{l}850000^{3} \\
\text { Rat }\end{array}$ & $\begin{array}{l}15000^{3} \\
\text { Rat }\end{array}$ & $\begin{array}{l}{ }^{1} \text { Camps et al., 2008; } \\
\text { 2Esteban et al., 2014 } \\
{ }^{3} \text { Wang L. et al., } 2014\end{array}$ \\
\hline & PF1901N & $>100^{2}$ & $>100^{2}$ & $790^{2}$ & $11^{2}$ & ${ }^{2}$ Esteban et al., 2014 \\
\hline & ASS234 & $\begin{array}{l}0.35^{4} \\
\text { Eel } \\
0.81^{2}\end{array}$ & $\begin{array}{l}0.46^{4} \\
\text { Eel } \\
1.82^{2}\end{array}$ & $\begin{array}{l}5.24^{4} \\
0.17^{2}\end{array}$ & $\begin{array}{l}43350^{4} \\
15830^{2}\end{array}$ & $\begin{array}{l}2 \text { Esteban et al., } 2014 \\
{ }^{4} \text { Bolea et al., } 2011\end{array}$ \\
\hline & Clorgyline & - & - & $0.42^{2}$ & $10660^{2}$ & ${ }^{2}$ Esteban et al., 2014 \\
\hline & L-Deprenyl & - & - & $630^{2}$ & $3.0^{2}$ & 2Esteban et al., 2014 \\
\hline
\end{tabular}

Enzymes activities were measured after 30 min incubation with the inhibitor; inhibition is for the human enzyme unless specified (marked in italics). The - indicates no inhibition. 
Altered MAO levels are associated with brain pathology. MAO A/B knockout mice displaying anxiety-like symptoms have greatly elevated monoamine levels (Chen et al., 2004). MAO B, located mainly in glial cells, increases with age and is elevated in AD and PD (Kennedy et al., 2003; Zellner et al., 2012; Woodard et al., 2014; Ooi et al., 2015). Inhibition of MAO B by compounds in cigarette smoke is associated with delayed onset of PD, and the MAO B inhibitor, deprenyl, delays the need to begin levodopa treatment in PD patients. Considering genetic variations, the A allele of the common A644G single nucleotide polymorphism in intron 13 of the MAO B gene is associated with slightly lower platelet MAO B activity and slightly less risk of PD (Liu et al., 2014). For MAO A, a low activity allele is associated with aggression (Gallardo-Pujol et al., 2013), and the high activity that results from the long repeat allele in the promotor region of the gene is associated with depression (Meyer et al., 2006), although a Positron Emission Tomography study found no significant difference in activity MAO A activity in the human brain (Fowler et al., 2015). Inhibition of MAO A has also been shown to decrease the oxidative stress that can result from the hydrogen peroxide and the aldehyde products of MAO catalysis both in heart and brain (Kaludercic et al., 2011; Ooi et al., 2015).

\section{MAO A and MAO B Structure, Activity, Redundancy}

MAO A and B share $70 \%$ homology and very similar active sites (reviewed in Edmondson et al., 2007). A major influence on substrate and inhibitor specificity is the narrow part ("gate") of the MAO B cavity defined by I199 and Y326 (Figure 2). However, the design of selective inhibitors is not simple, although in general MAO A can accommodate bulkier compounds. Simply changing one substituent can alter affinity for one form but not the other. For example, adding a second carbonitrile group to a small furan scaffold, increased the affinity for MAO A by 10 -fold but not for MAO B (Juárez-Jiménez et al., 2014) due to a hydrogen bond to asparagine 181 in MAO A. At that position (172 in MAO B) MAO B has a cysteine residue that can contribute to MAO Bselective binding. Structure-function analyses for the design of selective MAO inhibitors has been reviewed recently (Vilar et al., 2012; Patil et al., 2013; Carradori and Petzer, 2015).

Since MAO A and B are located on the $\mathrm{X}$ chromosome, human MAO deficiencies were first discovered in males. MAO A deficiency is associated with aggression, but MAO B deficient subjects were mentally normal. The combined deletion found in Norrie disease is associated with severe mental retardation (Brunner et al., 1993; Lenders et al., 1996). Detailed examination of the effects of deletions are now possible through knockout mice, studies that provide insight into the roles of MAO in behavior and development (Shih and Chen, 1999; Bortolato and Shih, 2011). In mice, as in humans, MAO A deficiency is associated with aggression. MAO B deficiency does not perturb monoamine metabolism to any great extent but results in excretion of higher amounts of phenylethylamine. The substrate specificities of the two forms overlap, with MAO A metabolizing serotonin well, MAO B PEA, but both dopamine and noradrenaline. The relative efficiency of catalysis by the two forms is best expressed by the maximum catalytic velocity divided by the $K_{\mathrm{M}}$, values; these can be found in (Youdim

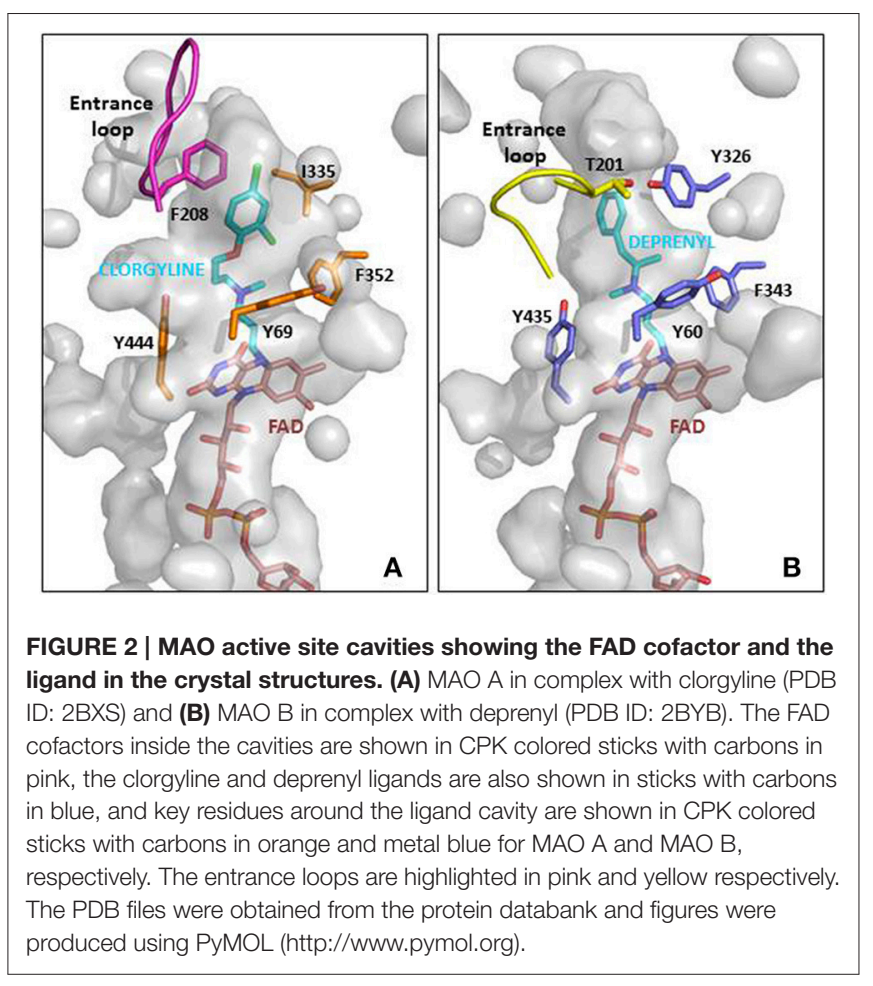

et al., 2006). In contrast to acetylcholine neurotransmission, the primary termination of the monoamine chemical signal is by reuptake of the monoamines, first into the neuron and then back into the storage vesicles. Inhibition of MAO increases stores of monoamines, for example in PD where inhibition of MAO B slows the breakdown of dopamine (Finberg, 2014).

\section{MAO A/B Assay and Inhibitors}

$\mathrm{MAO}$ can be assayed using absorbance or fluorescence changes, by radiolabeled product detection, by HPLC separation of the product, or by coupling the second product $\mathrm{H}_{2} \mathrm{O}_{2}$ to a detection system. The simplest assay is the measurement of the oxidation of kynuramine either continuously by the absorbance change at $314 \mathrm{~nm}$ (Weissbach et al., 1960) or in a stopped assay by the fluorescence of the product.

Recombinant human MAO A and MAO B expressed in insect cell membranes is now commercially available but the low activity requires the sensitive coupled assay where $\mathrm{H}_{2} \mathrm{O}_{2}$ is used by horseradish peroxidase to convert the non-fluorescent dye, N-acetyl-3,7-dihydroxyphenoxazine (Amplex Red), to the fluorescent resorufin (Zhou et al., 1997). As with all coupled assays, considerable care must be taken to check the validity of the assay by ensuring that the enzyme of interest (MAO in this case) is rate limiting. Inhibitors can quench or enhance fluorescence, or may inhibit horseradish peroxidase. These interfering factors must be checked for each type of inhibitor. It should be noted that Amplex Red, N-acetyl-3,7-dihydroxyphenoxazine, a structure similar to the MAO A inhibitor Methylene Blue (Ramsay et al., 2007; Milczek et al., 2011) inhibits MAO A so the dye must be used at $20-50 \mu \mathrm{M}$, and not the $200 \mu \mathrm{M}$ recommend by the assay kit manufacturer. Most substrates (except dopamine) can 
be used in this continuous coupled assay. The most frequently used is tyramine which has a $\mathrm{K}_{\mathrm{M}}$ of $127 \mu \mathrm{M}$ with MAO A and $107 \mu \mathrm{M}$ with MAO B (Youdim et al., 2006). However, different laboratories report various values, so the $\mathrm{K}_{\mathrm{M}}$ should be checked for each condition used.The discovery of highly selective reversible inhibitors for MAO A or MAO B has been the focus of compound synthesis for antidepressant design in recent years due to reduced side effects and lower drug-drug/food interaction risk. Some effective reversible inhibitors are harmine $\left(K_{\mathrm{i}}=5\right.$ nM) (Kim et al., 1997) used to measure MAO A occupancy in positron emission tomography scans (Sacher et al., 2011) and moclobemide (used in anxiety disorders). Moclobemide, giving 70-78\% occupancy of MAO A at clinically effective doses (Sacher et al., 2011), is useful because, as a reversible inhibitor, it does not inactivate the MAO A in the gut wall and so does not potentiate the vascular effects due to tyramine from the intestine. For MAO B, safinamide $\left(K_{\mathrm{i}}=0.5 \mu \mathrm{M}\right)$ (Binda et al., 2007 ) is in clinical trials for adjunct therapy in PD (Finberg, 2014). Traditional medicinal chemistry approaches, screening of compound libraries, and computational screening continue the search for new scaffolds for reversible inhibitors (Santana et al., 2006; Shelke et al., 2011).

However, irreversible inhibition and the slow turnover rate of MAO allows lower doses compared to reversible inhibitors and thus lower risk of side effects. All the common MAOI used clinically for depression and for $\mathrm{PD}$ are irreversible inhibitors (Table 1). The mechanism-based inactivation of MAO can be achieved by phenylzines, cyclopropopylamines, and propynamines. The selective irreversible inhibitors clorgyline for MAO A and deprenyl for MAO B both contain the propargyl moiety that after oxidation by MAO A forms a covalent adduct with the N5 of the FAD cofactor (Binda et al., 2002; De Colibus et al., 2005). The propargyl moiety is a useful small entity to add MAOI capability to molecules designed for other targets to give MTDL as describe below. The propargyl group must be oxidized by MAO to generate the reactive species that forms the covalent bond with the enzyme. The rate of inactivation by propargyl compounds for both MAO A and MAO B is around $0.2 \mathrm{~min}^{-1}$ with selectivity coming from the binding (Esteban et al., 2014; Malcomson et al., 2015). A further benefit of the propargyl moiety is its association with neuroprotection at levels lower than for inhibition of MAO (Naoi and Maruyama, 2010; Weinreb et al., 2011).

In assessing inhibitors of MAO, a final word of caution must be included regarding the considerable species differences that have been noted for inhibitor binding (Krueger et al., 1995). Happily, the human and rat sensitivities to MAOI are fairly similar but there are clear structural active site differences between the rat and human MAOs (Upadhyay et al., 2008) with implications for drug design (Novaroli et al., 2006; Fierro et al., 2007).

\section{Multi-Target Designed Ligands (MTDL) That Inhibit ChEs and MAOs}

One promising MTDL investigated under the auspices of COST Action CM1103 is ASS234 (N-((5-(3-(1-benzylpiperidin-4yl)propoxy)-1-methyl-1H-indol-2-yl)methyl)-N-methylprop-2yn-1-amine). The indole group aids MAO A selectivity and the propynamine (propargyl) group allows for irreversible inhibition. However, by adding a 1-benzylpiperidine fragment (similar to the AChE inhibitor, donepezil), this compound becomes also a reversible inhibitor for AChE and BChE (Bolea et al., 2011). During biological assessment, it became apparent that this compound has neuroprotective properties, by inhibiting $\mathrm{A} \beta 42$ and $\mathrm{A} \beta 40$ self-aggregation into plaques, and by protecting against depletion of antioxidative enzymes (Bolea et al., 2013). Therefore ASS234 has been patented (PCT/ES070186; WO2011/113988 A1) as a promising compound for the treatment of AD.Many other ChE/MAO targeted MTDL have been designed in the last 5 years, either propargyl-based (Youdim, 2013; Bautista-Aguilera et al., 2014b; Samadi et al., 2015; Weinreb et al., 2015) or coumarins derivatives (Pisani et al., 2011; Patil et al., 2013; Farina et al., 2015; Xie et al., 2015). The challenge will be to add further neuroprotective properties to progress to a disease-modifying drug.

\section{MITOCHONDRIAL HOMEOSTASIS AND APOPTOSIS}

\section{Mitochondrial Fusion, Fission, and Trafficking}

Mitochondria are dynamic organelles with the ability to divide (fission) and fuse (fusion) as well as to concentrate in particular subcellular locations. Regulation of these processes is crucial for cell health and apoptosis (Hales, 2004, 2010). Fission and fusion play critical roles in maintaining functional mitochondria when cells experience metabolic or environmental stresses, a reason why their improper regulation associates with several human genetic neurodegenerative diseases affecting to neuronal survival and plasticity (Hales, 2010; Youle and van der Bliek, 2012). Fusion is proposed to mitigate stress allowing complementation by mixing contents of partially damaged mitochondria. Fission, besides being required in the creation of new mitochondria, also contributes to quality control by facilitating both removal of damaged mitochondria (mitophagy) and apoptosis under cellular stress situations (Lee et al., 2004). The combined action of several GTPases contributes to the dynamic mitochondrial networks; Drp1/Dnm1 is key in mitochondrial division, mitofusins (Mfn1 and Mfn2) control outer mitochondrial membrane fusion, and OPA1 mediates inner mitochondrial membrane fusion (Griparic et al., 2004, 2007; Ishihara et al., 2006; Cohen et al., 2008). Neurons are more sensitive than other cells to mutations in the genes coding for these proteins, indicating the importance of mitochondrial dynamics for the maintenance of the nervous system integrity (Mandemakers et al., 2007). Deletion of either of the two mitofusins results in unbalanced fission and mitochondrial fragmentation (Koshiba et al., 2004). Mutations in Mfn2 cause the Charcot-Marie-Tooth disease (Züchner et al., 2004), and mutations in OPA1 are associated with genetic forms of blindness (Delettre et al., 2000) (Figure 3). A number of other factors contribute to modulate these GTPases activities and changes in their molecular shapes precisely control these processes (Mandemakers et al., 2007). For example, several brain neurodegenerative disorders cause decrease in mitochondrial size 


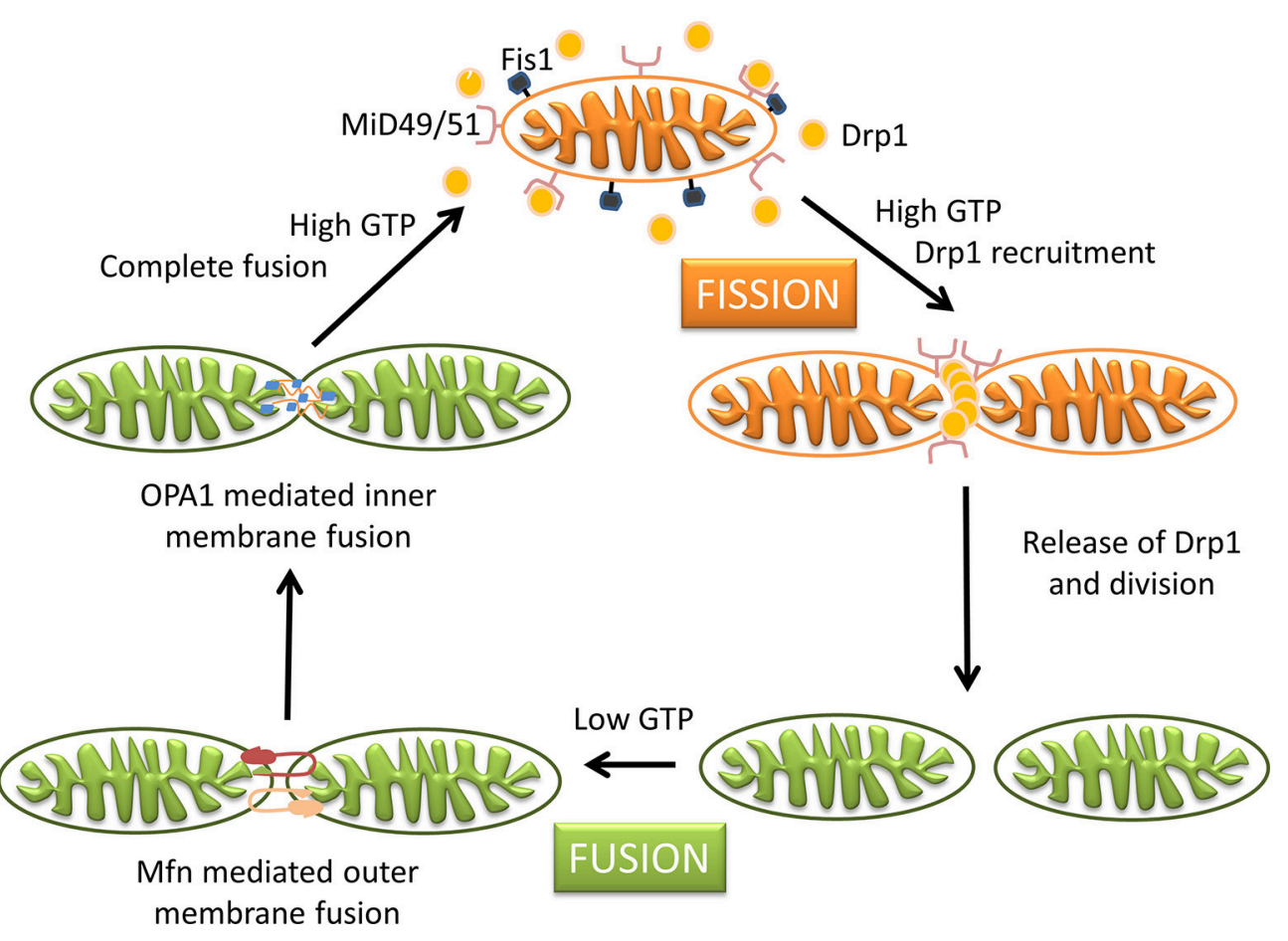

FIGURE 3 | Schematic representation of mitochondrial dynamics. Steady state mitochondrial morphology requires a balance of fission and fusion events. During organelle fission Drp1 is recruited from the cytosol to the outer mitochondrial membrane, where it interacts directly or indirectly with Fis 1 forming high molecular weight oligomers on the mitochondrial surface. This leads to constriction of mitochondria and sequential separation of the inner and outer membrane. Once Drp1 is released fission is complete. Fission also allows isolation for mitochondria that cannot be repaired followed by degradation through mitophagy, and is also important for subcellular distribution and transportation of mitochondria based on local energy needs. Mitochondrial fusion is a two-step process that requires outer and inner membrane fusion. Outer membrane fusion is facilitated by mitofusins tethering of adjacent membranes. This is subsequently followed by inner membrane fusion, which is GTP dependent and regulated by OPA1. Fusion allows for functional complementation and repair of damaged mitochondria.

and increased Drp1 translocation to mitochondria, increasing fission events. Treatments inhibiting Drp1 have been shown to restore mitochondrial length, reduce loss of new-born hippocampal neurons, and improve hippocampal-dependent learning and memory after damage (Li et al., 2015; Fischer et al., 2016). Therefore, reducing mitochondrial fission may contribute to rescue from brain injury, and the possibility to regulate the mechanisms of fusion and fission by different mediators in different tissues can represent a potential therapeutic target for related disorders.

Due to their complex structural and molecular features, neurons also require mechanisms for mitochondria trafficking to their distal destinations (presynaptic bouton, axons, synaptic terminals) and anchoring in regions where metabolism is in high demand. Failure to deliver a functional mitochondrion to the appropriate site within a neuron could contribute to neuronal dysfunction. Besides mitochondrial dynamics, the proteins mentioned above are also involved in mitochondrial subcellular positioning in neurons, ensuring a relatively constant mitochondrial population. As an example, membrane bound OPA1 influences mitochondrial elongation and transport in a Mfn1 dependent manner, while its soluble form regulates the tightness of mitochondrial cristae junctions and, therefore, release of apoptotic factors (Frezza et al., 2006) as well as cristae shape, which in turn, conditions supercomplex assembly (Cogliati et al., 2013). Mitochondria trafficking and anchoring mechanisms also rely on molecular motors (as KIF5 and dynein motors) which recruit mitochondria into stationary pools (Rintoul and Reynolds, 2010; Sheng and Cai, 2012; Sheng, 2014), and ensure neuronal mitochondria are adequately distributed where constant energy supply is crucial. Malfunctioning mitochondria are removed by mitophagy to minimize oxidative damage to the cell, with neurons again facing the challenge of their mitochondria being involved in distal processes located far from the cell body where lysosomes are abundant. The presence of functional lysosomes in axons has been evidenced to contribute to mitophagy of damaged mitochondria, and the local PINK1-Parkin-mediated mitophagy pathway provides rapid neuroprotection against oxidative stress without a requirement for retrograde transport to the soma (Ashrafi et al., 2014).

An imbalance of these processes involved in mitochondria dynamics and homeostasis (fission, fusion, trafficking, and mitophagy) can be detrimental to mitochondrial function, causing decreased respiration, ROS production, and apoptosis. All these are also symptoms caused by a traumatic brain injury, further indicating a prominent role of mitochondria in neuropathophysiology. 


\section{Mutations in Mitochondrial Proteins}

Mutations in other proteins with primary mitochondrial localization that cause abnormalities of protein conformation (mis-folding or aggregation) also result in neurodegenerative disorders. Examples include the kinase PANK2 involved in coenzyme A biosynthesis and degradation of some neurotransmitters, frataxin implicated in iron metabolism, PINK1 critical to prevent oxidative stress, or pitrilysin metallopeptidase which digests oligopeptides, including the mitochondrial fraction of amyloid-beta (Mandemakers et al., 2007; Brunetti et al., 2015). In addition, mutations in some non-mitochondrial proteins appear to affect mitochondrial function in neurodegeneration (such as superoxide dismutase 1, Parkin, $\alpha$-synuclein, MAO or the kinase LRRK2), although in general the role of most of these proteins in neurodegeneration must still be elucidated (Nakamura et al., 2011; Schapira and Gegg, 2011; Haddad and Nakamura, 2015).

\section{Apoptosis}

Apoptosis is a common type of cell death in neurodegenerative diseases, in which mitochondria make a major contribution to initiation of the death cascade (Petit et al., 1996; Naoi et al., 2006). Fission and fusion rates precisely regulate the number and morphology of mitochondria within a cell, with network fragmentation and cristae remodeling occurring during the early stages of apoptotic cell death (Wang and Youle, 2009; Youle and van der Bliek, 2012). In this context it is not surprising that proteins involved in mitochondrial morphology control also participate in apoptosis, and proteins associated with apoptosis regulation affect mitochondrial ultrastructure. Key apoptotic events in mitochondria include the release of caspase-dependent activators (cytochrome c) and caspase-independent apoptotic factors (the flavoenzyme apoptosis inducing factor, AIF), changes in electron transport, loss of mitochondrial transmembrane potential, altered cellular oxidation-reduction, and participation of pro- and anti- apoptotic Bcl-2 family proteins (Saraste and Pulkki, 2000; Edinger and Thompson, 2004). The different signals that converge on mitochondria to trigger or inhibit these events and their downstream effects delineate several major pathways in cell death (Wang and Youle, 2009).

As an example, AIF is an apoptotic factor that when released from the mitochondria and translocated to nucleus induces chromatin condensation and DNA fragmentation, while also having a vital role in mitochondria healthy cells (Susin et al., 1999; Miramar et al., 2001). Complex I (CI) dysfunction has long been associated with PD. AIF deficiency produces reduced levels of CI subunits, decreased CI activity, and impaired CI-dependent mitochondrial respiration (Vahsen et al., 2004; Urbano et al., 2005; Cheung et al., 2006). Although these AIF linked CI structural alterations have not been shown to cause dopaminergic neurodegeneration, an increase is the susceptibility of these neurons to exogenous PD neurotoxins has been proven (Perier et al., 2010, 2012). The exact role of AIF in intermembrane space of mitochondria of healthy cells has remained a conundrum, but several interesting novelties have been presented in the recent years regarding its redox activity in this organelle (Sevrioukova, 2009, 2011; Ferreira et al., 2014; Villanueva et al., 2015). Recently, it has also been described that the physical and functional $\mathrm{NADH}$-dependent interaction between AIF and the protein $\mathrm{CHCHD} 4$ regulates the correct assembly and maintenance of the respiratory chain complexes (Hangen et al., 2015; Meyer et al., 2015). CHCHD4 participates in mitochondrial protein import and catalyzes oxidative protein folding in cooperation with the sulfhydryl oxidase GFER/ALR/Erv1p (Chacinska et al., 2008; Banci et al., 2009; Fischer et al., 2013; Koch and Schmid, 2014). Upon interaction with $\mathrm{NADH}$, AIF undergoes reduction, with the concomitant dimerization and formation of highly stable charge transfer complexes. Both AIF dimers and charge transfer complexes are proposed to have a physiological function in a model where AIF would act as a sensor of the mitochondrial redox state (Churbanova and Sevrioukova, 2008; Ferreira et al., 2014; Sorrentino et al., 2015). In addition to the interplay with CHCHD4, AIF might also interact at the mitochondria with other proteins yet to be discovered.

Neurons are the cells that suffer larger effects upon deficiency of AIF, probably due to their high energetic dependency on the mitochondrial OXPHOS metabolism. In addition to AIF deficiency being related to different neurodegeneration types (Klein et al., 2002; Joza et al., 2005; van Empel et al., 2005; Cheung et al., 2006; Ishimura et al., 2008), six AIF pathological mutations have also been reported to produce human neurodegenerative diseases, with all patients with AIF mutations showing muscular atrophy, neuropathy and ataxia (Ghezzi et al., 2010; Berger et al., 2011; Rinaldi et al., 2012; Ardissone et al., 2015; Diodato et al., 2015; Kettwig et al., 2015). Thus, AIF appears as an essential protein for post-mitotic neuron survival, cerebellar development, and therefore, neurogenesis (Ishimura et al., 2008). AIF is also one of the proteins described to associate with OPA1 to cooperatively regulate and stabilize the respiratory chain, this interaction being proposed as one of the factors defining mitochondrial morphology (Cheung et al., 2006; Zanna et al., 2008).

The present therapeutics for neurodegenerative diseases are in general symptomatic and lack neuroprotective and neurorestorative properties, being not able to delay disease or modify its neuronal activity. In recent years, the development of multi-target neuroprotective and neurorestorative drugs with simultaneous action on enzymes such as cholinesterase, $\mathrm{BChE}$ and MAO A/B activities or being able to enhance the action of proteins intimately associated with mitochondrial biogenesis (Youdim, 2013; Youdim and Oh, 2013). A potential addition for this therapeutic strategy in neurodegenerative diseases is to halt common and progressive pathways for neural injury and cell death. In the current development of neuroprotective drugs, mitochondria are a key target to protect against cell death by preventing mitochondrial permeabilization, $\mathrm{Ca}^{2+}$ efflux, membrane potential decline and release of apoptotic factors while also inducing anti-apoptotic pro-survival proteins (Naoi et al., 2007; Weinreb et al., 2012, 2016, 2015). Connections between morphological regulation and the bioenergetics status of mitochondria are reciprocally responsive processes (Figure 4), with functional abnormality invoking morphological alterations in many human diseases and genetic defects in mitochondrial fusion/fission genes or insults 


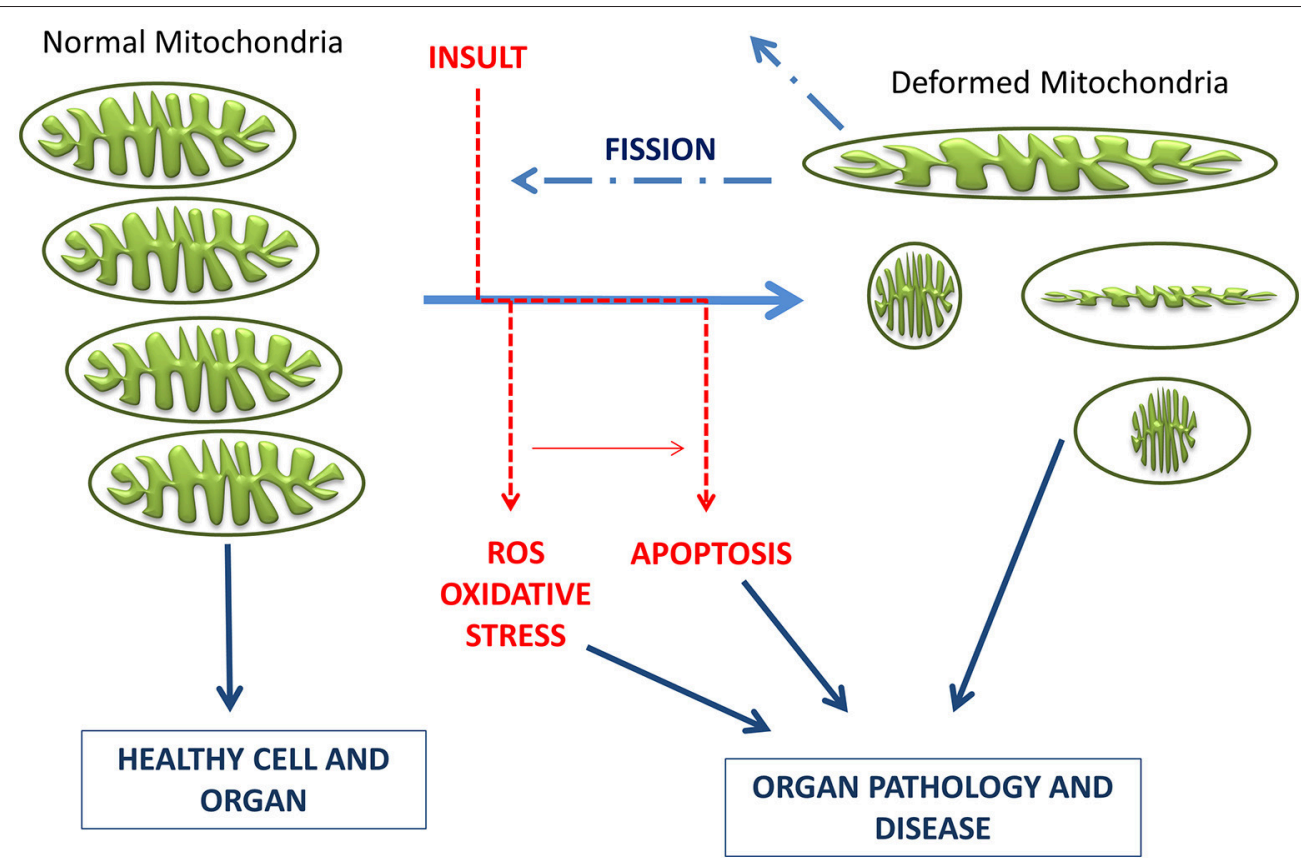

FIGURE 4 | Schematic representation of the timeline of mitochondrial bioenergetics and morphological changes inducing pathologies. Electrons leaking from the electron transport chain generate ROS, which damage mitochondrial membrane, mitochondrial DNA, and proteins. Neurons have limited defense against oxidative damage and are highly vulnerable to ROS. Damaged/depolarized mitochondria release cytochrome c that triggers cell death by activating caspases as well as AlF that initiates apoptosis in a caspase independent manner.

inducing mitochondrial deformation (accompanied by oxidative stress and/or apoptosis) causing human diseases of lethal consequence (Galloway et al., 2012, 2014; Westermann, 2012). In this context, controlling the mitochondrial morphology by manipulating fission and fusion emerges as a future therapeutic strategy to decrease the pathological outcome.

\section{ANTIOXIDANT PROPERTIES IN AN EXAMPLE MTDL}

Antioxidant properties, part of a desired pharmacologic profile for MTDLs designed to treat neurodegeneration, are screened by various in silico, in vitro and in vivo methods. Arising from the structure of the parent antioxidant drug stobadine (Horáková et al., 1994; Horáková and Stolc, 1998), several dozen derivatives with a hexahydropyridoindolic scaffold were synthesized and tested for their antioxidant and neuroprotective effect (Rackova et al., 2006; Stolc et al., 2006, 2010; Juranek et al., 2010). The aim of the new design was to use a wide knowledge of the pharmacological actions of stobadine to develop new substances with even higher antioxidant activity and reduced side effects. The screening confirmed the enhancement of the intrinsic radical scavenging activity of the 8-methoxy substituted derivatives, which was predicted for the right position of the electron-donating methoxy group. Several alkoxy-carbonyl substituents at the N2 position were tested to find sufficiently high lipophilicity and lower basicity of the molecule. From the compounds synthesized and tested ( \pm -cis-8-methoxy-2,3,4,4a,5,9b-hexahydro-1H-pyrido[4,3-

b]indole-2-carboxylic acid ethyl ester (SMe1EC2, Figure 5), which showed enhanced antioxidant properties near a lipophilic phase, was chosen for a detailed study.

SMe1EC2 had high intrinsic scavenging activity as measured with 1,1TM-diphenyl-2-picrylhydrazyl (DPPH) (Stefek et al., 2013). The initial velocity of DPPH decolorization by 50 $\mu \mathrm{M}$ SMe1EC2 $(0.507 \pm 0.003$ optical density(OD)/min) was comparable with that of equimolar trolox $(0.494 \pm$ $0.009 \mathrm{OD} / \mathrm{min})$. The parent compound stobadine at $50 \mu \mathrm{M}$ concentration was about three times less efficient $(0.156 \pm$ $0.019 \mathrm{OD} / \mathrm{min})$. The high intrinsic activity together with enhanced lipophilicity resulted in significantly higher antioxidant properties in rat brain homogenate or in a cellular model (red cells, macrophage RAW 264.7 cell cultures) when compared with stobadine (Stolc et al., 2006; Stefek et al., 2013; Balcerczyk et al., 2014). In the experiment with red blood cells two types of initiators of the haemolysis were used: hydrophilic AAPH (2,2'-azobis(2-amidinopropane) hydrochloride) and lipophilic $\mathrm{t}-\mathrm{BuOOH}$. While the activity of more hydrophilic and basic stobadine surpassed that of SMe1EC2 in AAPH induced haemolysis, SMe1EC2 exceeded stobadine in red blood cells protection when lipophilic $\mathrm{t}-\mathrm{BuOOH}$ was used (Stefek et al., 2013).

On a tissue level SMe1EC2 was able to recover the field action potential amplitude in CA1 region of rat hippocampal slices after $20 \mathrm{~min}$ reoxygenation following $6 \mathrm{~min}$ hypoxia to control value 


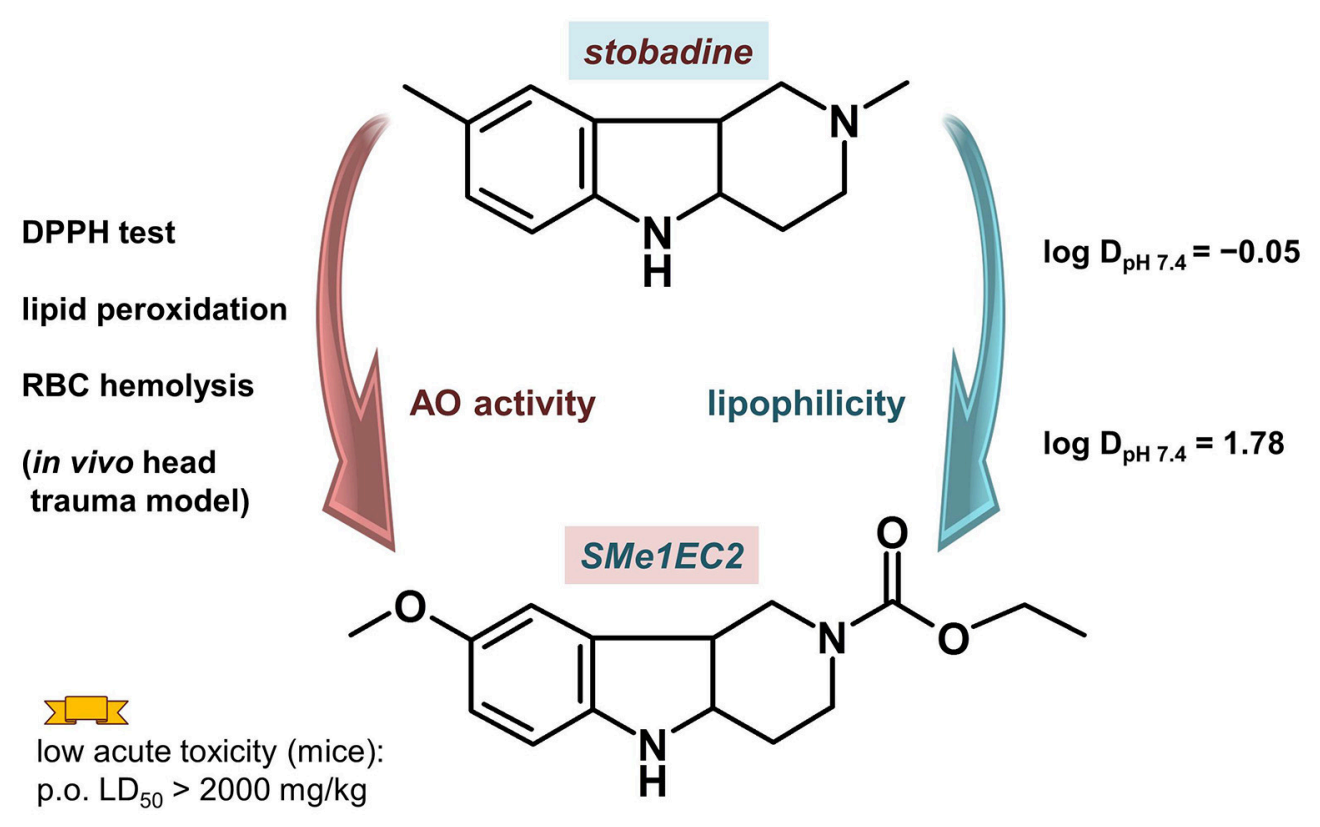

FIGURE 5 | Compound SMe1EC2 compared with the parent drug stobadine according to the structural, and in vitro and in vivo properties.

(100\%) at a concentration of $3 \mu \mathrm{mol} / \mathrm{l}$ (Stolc et al., 2006). The field action potential, created by the pyramidal neurons in the CA1 region after electric stimulation of Schäffer collaterals in the CA3 region and involving excitation of glutamatergic synapses, is an appropriate model for functional status of brain. Neuroprotective effects of the compound were shown also in rat hippocampal slices attacked by $\mathrm{Fe}^{2+}$ /ascorbic acid system (Gáspárová et al., 2010). Simultaneously, SMe1EC2 improved functional deficits and edema formation in rat hippocampus exposed to ischemia ex vivo after several days of oral treatment of rats (Gáspárová et al., 2009).

In order to estimate the in vivo neuroprotective potential of these new hexahydropyridoindoles, an experiment with acute head trauma model in mice has been performed (Stolc et al., $2006,2010,2011)$. There is a close relation between a traumatic head injury and a risk for later development of PD (Witcher et al., 2015; Xu et al., 2015). People aged 55 years and older who were treated in the hospital for traumatic brain injury were $44 \%$ more likely to develop PD over the next six years than those who sustained injuries, but not head injuries (Gardner et al., 2015). In the framework of the murine head trauma experiment the drugs were administered i.v. immediately after the trauma in single doses equimolar to $1 \mathrm{mg}$ of stobadine dihydrochloride, and $1 \mathrm{~h}$ later the total sensomotoric score was monitored. SMe1EC2 proved to be excellent compound in improvement of a total sensomotoric score (Stolc et al., 2006, 2011), achieving the value $244.33 \pm 50.20 \%$ ( $p=0.0036$ comparing to placebo) and exceeding such compounds as melatonin, stobadine and SPBN (2-sulfo- $\alpha$-phenyl-N-tert-butyl-nitrone). During this experiment brain oedema was also evaluated by brain wet weight assessment and brain histology. After triple i.v. administration of $1.14 \mathrm{mg} / \mathrm{kg}$ of SMe1EC2 in $1 \mathrm{~min}, 2 \mathrm{~h}$ and $24 \mathrm{~h}$ after Acute Head Trauma, the increase in brain wet weight induced by the trauma and culminating $5 \mathrm{~h}$ after the insult was significantly diminished almost to the control level. The reduction of the oedema, occurring especially in glial cells, was also proved histologically. Moreover, the occurrence of subdural bleeding, meningeal bleeding and bleeding in brain chambers throughout the whole follow-up period $(168 \mathrm{~h}$ ) was significantly reduced.

The compound was also tested for cell protection properties in the framework of diabetes-related pathological processes. AD and type 2 diabetes mellitus present many common features (de la Monte and Wands, 2008; Correia et al., 2012c; Ahmad, 2013). Both diseases are connected with malfunctions in glucose metabolism and mitochondria, elevated oxidative stress and activation of pro-inflammatory cytokines. SMe1EC2 enhanced the viability of cultured HT22 neuronal cells exposed to high glucose with simultaneous attenuating of parameters of the oxidations stress (Rackova et al., 2009). The compound also protected rat pancreatic INS-1E $\beta$ cell cultures against cytotoxic effects of hydrogen peroxide and inhibited profoundly the timedelayed apoptotic changes induced by the attack (Račková et al., 2011).

Besides metabolic disorders related to the high glucose plasma levels, pathologies connected with a high fat diet may also be related to neurodegeneration process (Morris et al., 2010). SMe1EC2 showed also efficiency in treating metabolic high-fat related disorders. In the rat model of hypertriglyceridemia it was shown that higher intake of cholesterol induced an increase in the number of active $\mathrm{Na}^{+} / \mathrm{K}^{+}$-ATPase molecules in HTG rats, which resulted in the increased retention of sodium. A threeweek treatment of animals kept on high cholesterol diet with SMe1EC2 in a dose of $10 \mathrm{mg} \mathrm{kg}^{-1}$ day $^{-1}$ normalized the function of renal $\mathrm{Na}^{+} /, \mathrm{K}^{+}$-ATPase to the level comparable in HTG rats 
fed with the standard diet. For a comparison, fenofibrate in a dose of $100 \mathrm{mg} \mathrm{kg}^{-1}$ day $^{-1}$ reversed the function of renal $\mathrm{Na}^{+}$/ $\mathrm{K}^{+}$-ATPase only slightly (Mézešová et al., 2012).

Further significant property of SMe1EC2 was its ability to protect endothelium under conditions of experimental diabetes of rats. It significantly decreased endothelaemia of diabetic rats and improved endothelium-dependent relaxation of arteries, slightly decreased ROS-production and increased bioavailability of nitric oxide in the aorta (Sotníková et al., 2011). Overall, the compound attenuated endothelial injury in diabetic animals. Although mechanism of this effect is still not clear, it could represent further positive effect in MTDL potential for treatment of neurodegenerative diseases.

Four ethological tests with rats (open field, elevated plusmaze, light/dark box exploration, forced swim test) were used to obtain information about anxiolytic and antidepressant activity of SMe1EC2 (Sedláčková et al., 2011). The substance was administered intraperitoneally $30 \mathrm{~min}$ before the tests at doses of 1,10 , and $25 \mathrm{mg} / \mathrm{kg}$. SMe1EC2 was found to exert anxiolytic activity in elevated plus maze with no affection of locomotor activity in a dose-dependent manner. The middle dose of SMe1EC2 resulted in similar anti-anxiety effect manifested in rats as that of diazepam (dose $2.5 \mathrm{mg} / \mathrm{kg}$ ). A medium anti-depressant activity was also predicted by combinatorial in silico methods (Majekova et al., 2013).

The acute toxicity of SMe1EC2 was assessed in mice after p.o. and i.v. administration. For p.o., it was estimated in GHS scale as 5, a compound with "comparatively low acute toxicity," with the $\mathrm{LD}_{50}$ value over $2000 \mathrm{mg} / \mathrm{kg}$. After i.v. administration, the $\mathrm{LD}_{50}$ of SMe1EC2 was $181.13 \mathrm{mg} / \mathrm{kg}$ (Stolc et al., 2006). The results of prenatal developmental toxicity study were similar: the compound demonstrated neither embryotoxic nor teratogenic effects on rat fetuses and no signs of maternal toxicity were found (Ujhazy et al., 2008).

Compound SMe1EC2 has been revealed to be a potential multi-target drug for neuronal diseases. Apart from its good distribution properties and high intrinsic radical scavenging activity, this is supported by the results of in vivo experiments on protection in the process of head trauma and diabetic damage of endothelium.

\section{CYTOCHROME P450}

The cytochrome P450 (CYP) family is involved in different steps of therapy from drug efficacy and dose requirement to adverse drug reactions and direct toxicity (Zanger and Schwab, 2013). There are 18 mammalian CYP isoenzymes, which encode 57 genes in the human genome (Nebert et al., 2013). Of these CYP isoenzymes, more than 10 belong to the CYP1, 2 , and 3 families and are responsible for the metabolism of more than $80 \%$ of xenobiotics and drugs used in therapy. This indicates that the CYP-dependent metabolism is one of the main factors in the regulation of drug concentration at a target level (pharmacokinetic effects) and is indeed involved in the adverse reactions of therapeutic compounds, in drug-drug interaction and their toxic effect. The low substrate specificity characterizing the CYP metabolism, is associated with the evidence of a large genetic polymorphism of some isoforms, particularly those involved in drug metabolism (i.e., CPY1A2, 2C9, 2C19, 2D6, and 3A4). Multi-allelic genetic polymorphisms, which remarkably depend on ethnicity, (Preissner et al., 2013) lead to distinct pharmacogenetic phenotypes termed as poor, extensive, and ultrarapid metabolizers. The loss of function promotes a reduced clearance with a consequent increase of plasma concentrations, while the gain of function leads to increased clearance and lower drug concentrations, resulting in increase and decrease effect of the drug, respectively, and potentially drug-related toxicity. These effects are not only related to genetic polymorphisms, but CYPs activity is regulated by chemicals and endogenous factors that can be promoted either by the induction or inhibition of some CYP activity. In the liver, most of the xenobiotic-metabolising CYPs are inducible, but one exception is CYP2D6. In general, control of protein expression can be exerted at the transcriptional mRNA, translational and posttranslational level. Posttranslational regulation has been described for CYP1A1, CYP1A2, CYP2E1 and CYP3A4 (Werlinder et al., 2001; Ingelman-Sundberg, 2004; Oesch-Bartlomowicz and Oesch, 2005; Smutny et al., 2013).

Pharmacoepigenomics is a new topic of research in the regulation of xenobiotic metabolizing enzymes. Up to now different studies indicate that DNA methylation and the numerous combinations of post-translational modifications of the histone proteins, are implicated in influencing the expression of genes whose products are engaged in drug metabolism. In addition, the increasing importance of the short regulatory miRNAs, has to be emphasized and initial studies show their involvement in regulating the expression of drug-metabolizing enzymes (Tsuchiya et al., 2006; Pan et al., 2009; IngelmanSundberg and Gomez, 2010).

Therefore, pharmacoepigenomics represents the future of research on drug metabolism, while the molecular mechanism of the transcriptional regulation of CYPs has been established and consolidated in several studies. Transcriptional control is of the highest importance and cytosolic receptors sensitive to the concentration of the environmental xenobiotics are crucial, namely the aryl hydrocarbon receptor (AhR), constitutive androgen receptor (CAR), the pregnane X-receptor (PXR), and peroxisome proliferator-activated receptor $(\operatorname{PPAR} \alpha)$. They regulate CYP forms as follows: CYP1A1, CYP1A2 and CYP2S1 (AhR), CYP2C9, CYP3A4 (PXR), CYP2B6, CYP2C9, CYP3A4 (CAR), and CYP4A family (PPAR $\alpha$ ) (Waxman, 1999; IngelmanSundberg, 2004).

All of these described regulatory mechanisms lead to the first of instances of interindividual variability in drug response, where a clear phenotypic consequence is evident in the population. Another aspect to take in account is the inhibition effects of CYP enzymes promoted by several drugs, chemicals, or diet components. This effect can increase systemic exposure, thereby causing severe toxic effects of the drug or of another concomitantly administered therapeutic compound that is metabolized by the same CYP(s) (Ludwig et al., 1999). The competition between chemicals for CYP activity has resulted in 
unpredictable pharmacokinetic interactions and can be a cause of drug-drug interactions, a major clinical problem.

\section{Cytochrome P450 in Brain and Its Role in Parkinson's Disease}

Most of these studies have been conducted in the liver which is the major organ involved in drug metabolism due to the high concentration of CYP in the endoplasmic reticulum of hepatocytes. However, the CYP families involved in xenobiotic metabolism are also expressed in extrahepatic tissues (i.e., intestine, brain, kidney). Since the expression of the majority of the isoforms appears to be very low compared the predominant expression in liver, and their role in overall total body clearance is lower, the basal expression and up-regulation in peripheral tissues can significantly affect local disposition of drugs or endogenous compounds and thus modify the pharmacological/toxicological effects or affect the distribution of xenobiotics in human body. In the brain, the overall level of CYP is $\sim 0.5-2 \%$ of that in liver microsomes (Miksys and Tyndale, 2013) and could play a role in tissue- and/or cellspecific sensitivity to certain drugs or xenobiotics. There have been a number of suggestions that environmental toxins may play a role in the pathogenesis of neurodegenerative disorders by directly damaging neurons or through bioactivation of some toxic compounds via CYPs (Riedl et al., 1999; Shahabi et al., 2008; Miksys and Tyndale, 2009; Ferguson and Tyndale, 2011; Vaglini et al., 2013).

In this context, it is underlined that studies with divergent results are addressed toward the allele mutation of gene that encodes CYP2D6. This isozyme is involved in the metabolism of exogenous drugs and neurotoxins including 1-methyl-4-phenyl1,2,3,6-tetrahydropyridine (MPTP, a neurotoxin that can cause selective dopaminergic neuronal damage) as well as endogenous compounds including dopamine (Payami et al., 2001). Recently Singh et al. (2014), in a study involving 70 PD patients, showed that a allelic variants of CYP2D6 and glutathione transferase1 were significantly associated with an increase in PD risk, due to a lower capability in the metabolism of neurotoxic compounds such as pesticides. This study is in agreement with the a metaanalysis performed by Lu et al. (2013) that demonstrated that an allele polymorphism of CYP2D6 increases the risk of Parkinson's disease.

On the contrary, other studies did not support an association between PD and mutations of the CYP2D6 and underline that $\mathrm{PD}$ is most likely the result of interactions between multiple genetic and environmental factors (Persad et al., 2003; Vilar et al., 2007; Halling et al., 2008). Whatever the cause of PD and other neurodegenerative disease, the knowledge of cytochrome P450 functions and metabolism is pivotal for its key roles in in vivo drug action, and why it plays a crucial function in the metabolism of toxic compounds.

\section{Cytochrome P450-Dependent Metabolism of MAO B Inhibitors and ASS234}

In the COST Action CM1103, a new family of multi-target molecules able to interact with AChE, as well as with MAO A and B, was synthesized by Samadi et al. (2011). These compounds bring together the benzylpiperidine and N-propargylamine moieties present in the AChE inhibitor donepezil and the MAO inhibitor PF9601N, respectively. The presence of propargyl moiety in the molecule confers particular susceptibility in terms of CYP-dependent metabolism. It is well-known that the terminal acetylenes can inhibit the CYP isoenzymes by alkylating the P450 prosthetic heme or by binding covalently to the protein with only partial loss of the catalytic activity. Sharma et al. (1996) demonstrated that both deprenyl and clorgyline are irreversible inhibitors of CYP2B1, by a mechanism-based inactivation due to the formation of a reactive intermediate based on their propargyl group. A recent study suggests that deprenyl can also inhibit CYP2B6 (Sridar et al., 2012). This isozyme is involved in the metabolism of Bupropion, an antidepressant often used to Parkinson's disease patients in conjunction with deprenyl, and its inhibition can lead to a potential drug interactions.

However, the inhibition of CYP $2 \mathrm{~B} 1$ and 2B6 does not promote inhibition of CYP-dependent metabolism of the drug. In fact deprenyl in humans, as well as in experimental animals, is rapidly metabolized by the liver cytochrome CYP system, forming mainly desmethydeprenyl and methamphetamine (Baker et al., 1999; Dragoni et al., 2003b). These two compounds are further metabolized to amphetamine. The CYP-dependent metabolism showed a high hepatic clearance that justifies the low half-life of the drug observed in vivo in humans $(\sim 0.15 \mathrm{~h})$ (Sridar et al., 2012).

It is important to note that both primary deprenyl metabolites can contribute to the therapeutic effect of the MAO-B inhibitor. Desmethyldeprenyl, a less potent inhibitor of MAO$\mathrm{B}$ than the parent drug both in vitro and in vivo, is more efficacious in protecting dopamine neurons against oxidative stress damage (Olanow and Tatton, 1999). The other metabolite, methamphetamine, is a more potent inhibitor of presynaptic noradrenaline and dopamine uptake than the parent drug and it has been suggested that this effect contributes to neuroprotection (Sziráki et al., 1994).

These metabolic pathways are also active in the CNS, as observed in vitro in microsomal preparations of monkey and mouse brain (Dragoni et al., 2003a). In contrast to deprenyl, PF9601N, the precursor of MTDL compounds studied in the COST CM 1103 project (Bolea et al., 2011), showed significantly lower liver clearance. The in vivo treatment of C57BL/6 mice did not modify cytochrome P450 and b5 content, and did not change NADPH-CYP-reductase or CYP2E1, 2A5, 1A1, 2B6, 3A activities. Furthermore, CYP-dependent metabolism of PF9601N by liver microsomes from either control or treated mice gave rise only to the formation of the desmethyl metabolite, FA72 (Dragoni et al., 2007). This desmethyl compound promoted a concentration-dependent inhibition of peroxinitrite oxidation with an $\mathrm{IC}_{50}$ value lower than the parent compound and than deprenyl. Furthermore, PF9601N and its metabolite were able to strongly inhibit rat brain neuronal nitric oxide synthase, (NOS) in contrast to observations with deprenyl, which caused a slight decrease of the enzyme activity only at millimolar concentration (Bellik et al., 2010). 


\section{CYP-dependent metabolism of ASS234}

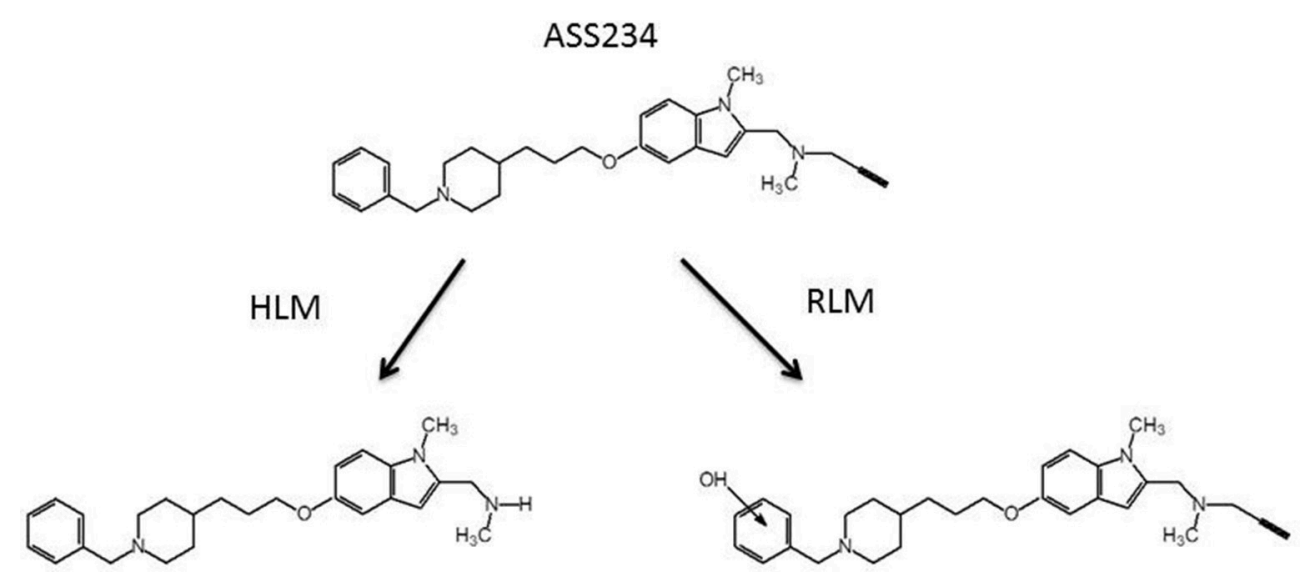

FIGURE 6 | Cytochrome P450-dependent metabolism of ASS234 in human (HLM) and rat (RLM) liver microsomal preparations. ASS234 (25 $\mu$ M) was incubated at $37^{\circ} \mathrm{C}$ in phosphate buffer in the presence of microsomes for $30 \mathrm{~min}$.

These observations led us to study the CYP-dependent metabolism of ASS234 (Marco-Contelles et al., 2016). ASS234 was incubated in phosphate buffer with human or rat hepatic microsomal preparations (HLM and RLM, respectively) as previously reported (D'Elia et al., 2009). Samples were analyzed by Agilent UHD Accurate-Mass Q-TOF LC/MS and the experimental data obtained were elaborated using MassMetaSite, a computer assisted method for the interpretation of LC-MSMS data that combines prediction of a compound's site of metabolism (SoM) with the processing of MS spectra and rationalization based on fragment analysis (Strano-Rossi et al., 2014). The kinetic analysis indicated that the substrate depletion followed a mono-exponential relationship either in presence of HLM and RLM. RLM metabolized the compound at a higher rate compared to HLM. In fact, after 30 min incubation only $23 \%$ of ASS234 was metabolized by human preparations, while RLM preparations were able to metabolized more than the $80 \%$ of initial amount $(10 \mu \mathrm{M})$ of substrate (Simone et al., 2014).

The MS analysis of the products from ASS234 metabolism showed two different pathways as shown in Figure 6. The principal metabolite observed with HLM resulted in a compound at $[\mathrm{M}-38]^{+}(\mathrm{m} / \mathrm{z})$ indicating the formation of $\mathrm{N}$-depropargylated metabolite, in agreement with that observed for the CYPdependent metabolism of PF9601N (Dragoni et al., 2007). On the contrary, in RLM preparations, the major metabolite resulted in $\mathrm{m} / \mathrm{z}$ equal to $[\mathrm{M}+16]^{+}$, which corresponded to the hydroxylated derivative on the benzene ring. Other minor peaks were present in both microsomal preparations and resulted in, as secondary metabolites, the $\mathrm{N}$-demethylated derivatives either on tertiary amine or indole nitrogen. The in silico analysis indicated that CYP2D6 and 2C19 are the major CYPs involved in the human metabolism of ASS234 (Simone et al., 2014).

Taken together, this information clearly indicates that ASS234 is a poor $\mathrm{CYP}(\mathrm{s})$ substrate in human liver, that the resulting metabolite should be not a MAO inhibitor, but that the inhibition effect on AChE should remain. Furthermore, in accord with the observations with PF9601N (Dragoni et al., 2007), the ASS234 CYP-dependent metabolite can be a more potent antioxidant and NOS inhibitor than the parent compound.

However, the involvement of CYP2D6 and 2C19, two highly genetic polymorphic cytochrome $\mathrm{P} 450$ s, require more care due to possible toxic effects of the parent compound having a lower metabolic clearance. Moreover, the evidence that human and rat present two different metabolic behaviors, in terms of velocity and metabolite formation, underlines the differences between species in CYP-dependent metabolism and the danger of attempting to extrapolate results across species.

\section{CONCLUSION}

In the last century pharmacological research was driven to discover highly selective drugs. This strategy has failed, in part, because it is seen that the interaction with a single target, either receptor or enzyme, can promote compensatory adaptations in the living organisms leading to a failure of the therapy. These observations and the discovery that different pathologies have common aspects has led to the synthesis of new molecules that can interact with multiple targets with the aim to improved balance of efficacy and safety compared to single targeting drugs.

We have reviewed the major targets for the assessment of MTDL relevant to neurodegenerative diseases, giving examples of compounds generated by our collaborating medicinal chemists in COST Action CM1103. Mitochondria are highlighted as the area of future interest but the many possible targets will have to be refined to those most influential on progression in each specific disease. It is becoming recognized, particularly for mitochondrial function, that the cumulative effect of small inefficiencies can trigger pathology under additional insult such as oxidative stress. Recent advances in cell biology techniques have enabled the study 
of factors involved in mitochondrial dynamics. The processes vital to mitochondrial health are also vital to neuronal survival and will provide the challenge to discover new tools to prevent neurodegeneration. When single target efficacy is achieved, then new modalities can be added to MTDL for the ultimate prevention of neuropathology.

\section{AUTHOR CONTRIBUTIONS}

All authors contributed to the writing of the manuscript. MV and RR integrated and revised it.

\section{REFERENCES}

Ahmad, W. (2013). Overlapped metabolic and therapeutic links between Alzheimer and diabetes. Mol. Neurobiol. 47, 399-424. doi: 10.1007/s12035-0128352-z

Anand, P., and Singh, B. (2013). A review on cholinesterase inhibitors for Alzheimer's disease. Arch. Pharmac. Res. 36, 375-399. doi: 10.1007/s12272-0130036-3

Ardissone, A., Piscosquito, G., Legati, A., Langella, T., Lamantea, E., Garavaglia, B., et al. (2015). A slowly progressive mitochondrial encephalomyopathy widens the spectrum of AIFM1 disorders. Neurology 84, 2193-2195. doi: 10.1212/WNL.0000000000001613

Arendt, T., Brückner, M. K., Lange, M., and Bigl, V. (1992). Changes in acetylcholinesterase and butyrylcholinesterase in alzheimers-disease resemble embryonic-development - a study of molecular-forms. Neurochem. Int. 21, 381-396. doi: 10.1016/0197-0186(92)90189-X

Ashrafi, G., Schlehe, J. S., LaVoie, M. J., and Schwarz, T. L. (2014). Mitophagy of damaged mitochondria occurs locally in distal neuronal axons and requires PINK1 and Parkin. J. Cell Biol. 206, 655-670. doi: 10.1083/jcb.201401070

Baker, G. B., Urichuk, L. J., McKenna, K. F., and Kennedy, S. H. (1999). Metabolism of monoamine oxidase inhibitors. Cell. Mol. Neurobiol. 19, 411-426. doi: 10.1023/A:1006982732681

Balcerczyk, A., Bartosz, G., Drzewinska, J., Piotrowski, L., Pulaski, L., and Stefek, M. (2014). Antioxidant action of SMe1EC2, the low-basicity derivative of the pyridoindole stobadine, in cell free chemical models and at cellular level. Interdiscipl. Toxicol. 7, 27-32. doi: 10.2478/intox-2014-0005

Banci, L., Bertini, I., Cefaro, C., Ciofi-Baffoni, S., Gallo, A., Martinelli, M., et al. (2009). MIA40 is an oxidoreductase that catalyzes oxidative protein folding in mitochondria. Nat. Struct. Mol. Biol. 16, 198-206. doi: 10.1038/nsmb.1553

Bartolini, M., Bertucci, C., Cavrini, V., and Andrisano, V. (2003). $\beta$-amyloid aggregation induced by human acetylcholinesterase: inhibition studies. Biochem. Pharmacol. 65, 407-416. doi: 10.1016/S0006-2952(02)01514-9

Bartzokis, G., and Tishler, T. A. (2000). MRI evaluation of basal ganglia ferritin iron and neurotoxicity in Alzheimer's and Huntingon's disease. Cell. Mol. Biol (Noisy-le-grand). 46, 821-833.

Bautista-Aguilera, O. M., Esteban, G., Bolea, I., Nikolic, K., Agbaba, D., Moraleda, I., et al. (2014a). Design, synthesis, pharmacological evaluation, QSAR analysis, molecular modeling and ADMET of novel donepezil-indolyl hybrids as multipotent cholinesterase/monoamine oxidase inhibitors for the potential treatment of Alzheimer's disease. Eur. J. Med. Chem. 75, 82-95. doi: 10.1016/j.ejmech.2013.12.028

Bautista-Aguilera, O. M., Samadi, A., Chioua, M., Nikolic, K., Filipic, S., Agbaba, D., et al. (2014b). N-Methyl-N-((1-methyl-5-(3-(1-(2-methylbenzyl)piperidin4yl).propoxy).-1H- indol-2-yl).methyl)prop-2-yn-1-amine, a New Cholinesterase and Monoamine Oxidase Dual. J. Med. Chem. 57, 10455-10463. doi: $10.1021 / j m 501501$ a

Bazzu, G., Rocchitta, G., Migheli, R., Alvau, M. D., Zinellu, M., Puggioni, G., et al. (2013). Effects of the neurotoxin MPTP and pargyline protection on extracellular energy metabolites and dopamine levels in the striatum of freely moving rats. Brain Res. 1538, 159-171. doi: 10.1016/j.brainres.2013.09.037

Bellik, L., Dragoni, S., Pessina, F., Sanz, E., Unzeta, M., and Valoti, M. (2010). Antioxidant properties of PF9601N, a novel MAO-B inhibitor: assessment of

\section{ACKNOWLEDGMENTS}

This article is based upon work from COST Action CM1103 "Structure-based drug design for diagnosis and treatment of neurological diseases: dissecting and modulating complex function in the monoaminergic systems of the brain," supported by COST (European Cooperation in Science and Technology). The authors thank the participants in COST Action for productive collaborations. MMajekova acknowledges the support of VEGA 2/0033/14, and MMedina the support of MINECO, Spain (BIO2013-42978-P).

its ability to interact with reactive nitrogen species. Acta. Biochim. Pol. 57, 235-239.

Benek, O., Aitken, L., Hroch, L., Kuca, K., Gunn-Moore, F., and Musilek, K. (2015). A direct interaction between mitochondrial proteins and amyloid-beta peptide and its significance for the progression and treatment of Alzheimer's Disease. Curr. Med. Chem. 22, 1056-1085. doi: 10.2174/0929867322666150114 163051

Berger, I., Ben-Neriah, Z., Dor-Wolman, T., Shaag, A., Saada, A., Zenvirt, S., et al. (2011). Early prenatal ventriculomegaly due to an AIFM1 mutation identified by linkage analysis and whole exome sequencing. Mol. Genet. Metabolism 104, 517-520. doi: 10.1016/j.ymgme.2011.09.020

Bernardi, P., Di Lisa, F., Fogolari, F., and Lippe, G. (2015). From ATP to PTP and Back: a dual function for the Mitochondrial ATP Synthase. Circ. Res. 116, 1850-1862. doi: 10.1161/CIRCRESAHA.115.306557

Binda, C., Newton-Vinson, P., Hubalek, F., Edmondson, D. E., and Mattevi, A. (2002). Structure of human monoamine oxidase B, a drug target for the treatment of neurological disorders. Nat. Struct. Biol. 9, 22-26. doi: $10.1038 / \mathrm{nsb} 732$

Binda, C., Valente, S., Romanenghi, M., Pilotto, S., Cirilli, R., Karytinos, A., et al. (2010). Biochemical, Structural, and Biological Evaluation of Tranylcypromine derivatives as inhibitors of Histone Demethylases LSD1 and LSD2. J. Am. Chem. Soc. 132, 6827-6833. doi: 10.1021/ja101557k

Binda, C., Wang, J., Pisani, L., Caccia, C., Carotti, A., Salvati, P., et al. (2007). Structures of human monoamine oxidase B complexes with selective noncovalent inhibitors: Safinamide and coumarin analogs. J. Med. Chem. 50, 5848-5852. doi: 10.1021/jm070677y

Bird, M. J., Thorburn, D. R., and Frazier, A. E. (2014). Modelling biochemical features of mitochondrial neuropathology. Biochim. Biophys. Acta. 1840, 1380-1392. doi: 10.1016/j.bbagen.2013.10.017

Bolea, I., Colivicchi, M. A., Ballini, C., Marco-Contelles, J., Tipton, K. F., Unzeta, M., et al. (2014). Neuroprotective effects of the MAO-B inhibitor, PF9601N, in an in vivo model of excitotoxicity. CNS Neurosci. Ther. 20, 641-650. doi: $10.1111 / \mathrm{cns} .12271$

Bolea, I., Gella, A., Monjas, L., Perez, C., Rodriguez-Franco, M. I., MarcoContelles, J., et al. (2013). Multipotent, Permeable Drug ASS234 Inhibits A beta Aggregation, possesses antioxidant properties and protects from a beta-induced Apoptosis in vitro. Curr. Alzheimer Res. 10, 797-808. doi: $10.2174 / 15672050113109990151$

Bolea, I., Juarez-Jimenez, J., de los Rios, C., Chioua, M., Pouplana, R., Javier Luque, F., et al. (2011). Synthesis, biological evaluation, and molecular modeling of donepezil and $\mathrm{N}$-[(5-(benzyloxy).-1-methyl-1Hindol-2-yl).methyl]-N-methylprop-2-yn-1-amine hybrids as new multipotent cholinesterase/monoamine oxidase inhibitors for the treatment of Alzheimer's Disease. J. Med. Chem. 54, 8251-8270. doi: 10.1021/jm200853t

Bolognesi, M. L., Cavalli, A., Valgimigli, L., Bartolini, M., Rosini, M., Andrisano, V., et al. (2007). Multi-target-directed drug design strategy: from a dual binding site acetylcholinesterase inhibitor to a trifunctional compound against Alzheimer's disease. J. Med. Chem. 50, 6446-6449. doi: 10.1021/jm701225u

Bonivento, D., Milczek, E. M., McDonald, G. R., Binda, C., Holt, A., Edmondson, D. E., et al. (2010). Potentiation of ligand binding through cooperative effects in monoamine oxidase B. J. Biol. Chem. 285, 36849-36856. doi: 10.1074/jbc.M110.169482 
Borger, E., Aitken, L., Du, H., Zhang, W., Gunn-Moore, F. J., and Yan, S. S. (2013). Is amyloid binding alcohol dehydrogenase a drug target for treating Alzheimer's disease? Curr. Alzheimer Res. 10, 21-29. doi: 10.2174/1567205011310 010004

Bortolato, M., and Shih, J. C. (2011). Behavioral outcomes of monoamine oxidase deficiency: preclinical and clinical evidence. Int. Rev. Neurobiol. 100, 13-42. doi: 10.1016/b978-0-12-386467-3.00002-9

Brunetti, D., Torsvik, J., Dallabona, C., Teixeira, P., Sztromwasser, P., FernandezVizarra, E., et al. (2015). Defective PITRM1 mitochondrial peptidase is associated with $\mathrm{A} \beta$ amyloidotic neurodegeneration. EMBO Mol. Med. 8, 176-190 doi: 10.15252/emmm.201505894

Brunner, H. G., Nelen, M., Breakefield, X. O., Ropers, H. H., and Vanoost, B. A. (1993). Abnormal behavior associated with a point mutation in the structural gene for monoamine oxidase-A. Science 262, 578-580. doi: $10.1126 /$ science. 8211186

Butterfield, D. A., Di Domenico, F., Swomley, A. M., Head, E., and Perluigi, M. (2014). Redox proteomics analysis to decipher the neurobiology of Alzheimerlike neurodegeneration: overlaps in Down's syndrome and Alzheimer's disease brain. Biochem. J. 463, 177-189. doi: 10.1042/BJ20140772

Camps, P., Formosa, X., Galdeano, C., Gómez, T., Munoz-Torrero, D., Scarpellini, M., et al. (2008). Novel donepezil-based inhibitors of acetyland butyrylcholinesterase and acetylcholinesterase-induced beta-amyloid aggregation. J. Med. Chem. 51, 3588-3598. doi: 10.1021/jm8001313

Carradori, S., and Petzer, J. P. (2015). Novel monoamine oxidase inhibitors: a patent review (2012-2014). Expert Opin. Ther. Pat. 25, 91-110. doi: $10.1517 / 13543776.2014 .982535$

Chacinska, A., Guiard, B., Müller, J. M., Schulze-Specking, A., Gabriel, K., Kutik, S., et al. (2008). Mitochondrial biogenesis, switching the sorting pathway of the intermembrane space receptor Mia40. J. Biol. Chem. 283, 29723-22979. doi: 10.1074/jbc.M805356200

Chen, K., Holschneider, D. P., Wu, W. H., Rebrin, I., and Shih, J. C. (2004). A spontaneous point mutation produces monoamine oxidase A/B knock-out mice with greatly elevated monoamines and anxiety-like behavior. J. Biol. Chem. 279, 39645-39652. doi: 10.1074/jbc.M405550200

Cheung, E. C., Joza, N., Steenaart, N. A., McClellan, K. A., Neuspiel, M., McNamara, S., et al. (2006). Dissociating the dual roles of apoptosis-inducing factor in maintaining mitochondrial structure and apoptosis. EMBO J. 25, 4061-4073. doi: 10.1038/sj.emboj.7601276

Cheung, J., Rudolph, M. J., Burshteyn, F., Cassidy, M. S., Gary, E. N., Love, J., et al. (2012). Structures of Human acetylcholinesterase in complex with pharmacologically important ligands. J. Med. Chem. 55, 10282-10286. doi: 10.1021/jm300871x

Cho, S., and Hu, Y. (2007). Activation of 5-HT4 receptors inhibits secretion of beta-amyloid peptides and increases neuronal survival. Exp. Neurol. 203, 274-278. doi: 10.1016/j.expneurol.2006.07.021

Churbanova, I. Y., and Sevrioukova, I. F. (2008). Redox-dependent changes in molecular properties of mitochondrial apoptosis-inducing factor. J. Biol. Chem. 283, 5622-5631. doi: 10.1074/jbc.M709147200

Cochet, M., Donneger, R., Cassier, E., Gaven, F., Lichtenthaler, S. F., Marin, P., et al. (2013). 5-HT4 receptors constitutively promote the non-amyloidogenic pathway of APP cleavage and interact with ADAM10. ACS Chem. Neurosci. 4, 130-140. doi: 10.1021/cn300095t

Cogliati, S., Frezza, C., Soriano, M. E., Varanita, T., Quintana-Cabrera, R., Corrado, M., et al. (2013). Mitochondrial cristae shape determines respiratory chain supercomplexes assembly and respiratory efficiency. Cell 155, 160-171. doi: 10.1016/j.cell.2013.08.032

Cohen, M. M., Leboucher, G. P., Livnat-Levanon, N., Glickman, M. H., and Weissman, A. M. (2008). Ubiquitin-proteasome-dependent degradation of a mitofusin, a critical regulator of mitochondrial fusion. Mol. Biol. Cell. 19, 2457-2464. doi: 10.1091/mbc.E08-02-0227

Correia, S. C., Carvalho, C., Cardoso, S., Santos, R. X., Santos, M. S., Oliveira, C. R., et al. (2010a). Mitochondrial preconditioning: a potential neuroprotective strategy. Front. Aging. Neurosci. 2:138. doi: 10.3389/fnagi.2010.00138

Correia, S. C., Santos, R. X., Cardoso, S., Carvalho, C., Candeias, E., Duarte, A. I., et al. (2012a). Alzheimer disease as a vascular disorder: where do mitochondria fit? Exp. Gerontol. 47, 878-886 doi: 10.1016/j.exger.2012.07.006

Correia, S. C., Santos, R. X., Carvalho, C., Cardoso, S., Candeias, E., Santos, M. S., et al. (2012c). Insulin signaling, glucose metabolism and mitochondria: major players in Alzheimer's disease and diabetes interrelation. Brain Res. 1441, 64-78. doi: 10.1016/j.brainres.2011.12.063

Correia, S. C., Santos, R. X., Perry, G., Zhu, X., Moreira, P. I., and Smith, M. A. (2010b). Mitochondria: the missing link between preconditioning and neuroprotection. J. Alzheimers. Dis. 20(Suppl. 2), S475-S485. doi: 10.3233/JAD2010-100669

Correia, S. C., Santos, R. X., Perry, G., Zhu, X., Moreira, P. I., and Smith, M. A. (2012b). Mitochondrial importance in Alzheimer's, Huntington's and Parkinson's diseases. Adv. Exp. Med. Biol. 724, 205-221. doi: 10.1007/978-14614-0653-2_16

Costanzo, M., and Zurzolo, C. (2013). The cell biology of prion-like spread of protein aggregates: mechanisms and implication in neurodegeneration. Biochem. J. 15, 1-17. doi: 10.1042/BJ20121898

Csermely, P., Agoston, V., and Pongor, S. (2005). The efficiency of multi-target drugs: the network approach might help drug design. Trends Pharmacol. Sci. 26, 178-182. doi: 10.1016/j.tips.2005.02.007

Darvesh, S., Cash, M. K., Reid, G. A., Martin, E., Mitnitski, A., and Geula, C. (2012). Butyrylcholinesterase is associated with beta-amyloid plaques in the Transgenic APP(SWE)/PSEN1dE9 Mouse Model of Alzheimer Disease. J. Neuropathol. Exp. Neurol. 71, 2-14. doi: 10.1097/NEN.0b013e31823cc7a6

De Colibus, L., Li, M., Binda, C., Lustig, A., Edmondson, D. E., and Mattevi, A. (2005). Three-dimensional structure of human monoamine oxidase A (MAO A).: relation to the structures of rat MAO A and human MAO B. Proc. Natl. Acad. Sci. U.S.A. 102, 12684-12689. doi: 10.1073/pnas.0505975102

de la Monte, S. M., and Wands, J. R. (2008). Alzheimer's disease is type 3 diabetes - evidence reviewed. J. Diabetes Sci. Technol. 2, 1101-1113. doi: 10.1177/193229680800200619

Delettre, C., Lenaers, G., Griffoin, J. M., Gigarel, N., Lorenzo, C., Belenguer, P., et al. (2000). Nuclear gene OPA1, encoding a mitochondrial dynamin-related protein, is mutated in dominant optic atrophy. Nat. Genet. 26, 207-210. doi: $10.1038 / 79936$

D’Elia, P., De Matteis, F., Dragoni, S., Shah, A., Sgaragli, G., and Valoti, M. (2009). DP7, a novel dihydropyridine multidrug resistance reverter, shows only weak inhibitory activity on human CYP3A enzyme(s). Eur. J. Pharmacol. 614, 7-13. doi: 10.1016/j.ejphar.2009.04.019

Diodato, D., Tasca, G., Verrigni, D., D’Amico, A., Rizza, T., Tozzi, G., et al. (2015). A novel AIFM1 mutation expands the phenotype to an infantile motor neuron disease. Eur. J. Hum. Genet. 24, 463-466. doi: 10.1038/ejhg.2015.141

Donmez, G. (2012). The neurobiology of sirtuins and their role in neurodegeneration. Trends Pharmacol. Sci. 33, 494-501. doi: 10.1016/j.tips. 2012.05.007

Dragoni, S., Bellik, L., Frosini, M., Matteucci, G., Sgaragli, G., and Valoti, M. (2003a). Cytochrome P450-dependent metabolism of 1-deprenyl in monkey (Cercopithecus aethiops) and C57BL/6 mouse brain microsomal preparations. J. Neurochem. 86, 1174-1180. doi: 10.1046/j.1471-4159.2003.01927.x

Dragoni, S., Bellik, L., Frosini, M., Sgaragli, G., Marini, S., Gervasi, P. G., et al. (2003b). l-Deprenyl metabolism by the cytochrome P450 system in monkey (Cercopithecus aethiops) liver microsomes. Xenobiotica 33, 181-195. doi: 10.1080/0049825021000048827

Dragoni, S., Materozzi, G., Pessina, F., Frosini, M., Marco, J. L., Unzeta, M., et al. (2007). CYP-dependent metabolism of PF9601N, a new monoamine oxidase-B inhibitor, by C57BL/6 mouse and human liver microsomes. J. Pharm. Pharm. Sci. 10, 473-485. doi: 10.18433/J37P4J

Eckert, G. P., Renner, K., Eckert, S. H., Eckmann, J., Hagl, S., Abdel-Kader, R. M., et al. (2012). Mitochondrial Dysfunction-A Pharmacological Target in Alzheimer's Disease. Mol. Neurobiol. 46, 136-150. doi: 10.1007/s12035-0128271-z

Edinger, A. L., and Thompson, C. B. (2004). Death by design: apoptosis, necrosis and autophagy. Curr. Opin. Cell. Biol. 16, 663-669. doi: 10.1016/j.ceb.2004 09.011

Edmondson, D. E., Binda, C., and Mattevi, A. (2007). Structural insights into the mechanism of amine oxidation by monoamine oxidases A and B. Arch. Biochem. Biophys. 464, 269-276. doi: 10.1016/j.abb.2007.05.006

Ellman, G. L., Courtney, K. D., Andres, V., and Featherstone, R. M. (1961). A New and Rapid Colorimetric Determination of Acetylcholinesterase Activity. Biochem. Pharmacol. 7, 88-95. doi: 10.1016/0006-2952(61)90145-9

Esteban, G., Allan, J., Samadi, A., Mattevi, A., Unzeta, M., Marco-Contelles, J., et al. (2014). Kinetic and structural analysis of the irreversible inhibition of 
human monoamine oxidases by ASS234, a multi-target compound designed for use in Alzheimer's disease. Biochim. Biophys. Acta 1844, 1104-1110. doi: 10.1016/j.bbapap.2014.03.006

Eyer, P., Worek, F., Kiderlen, D., Sinko, G., Stuglin, A., Simeon-Rudolf, V., et al. (2003). Molar absorption coefficients for the reduced Ellman reagent: reassessment. Anal. Biochem. 312, 224-227. doi: 10.1016/S00032697(02)00506-7

Farina, R., Pisani, L., Catto, M., Nicolotti, O., Gadaleta, D., Denora, N., et al. (2015). Structure-based design and optimization of multitargetDirected 2H-Chromen-2-one derivatives as potent inhibitors of Monoamine Oxidase B and Cholinesterases. J. Med. Chem. 58, 5561-5578. doi: 10.1021/acs.jmedchem.5b00599

Ferguson, C. S., and Tyndale, R. F. (2011). Cytochrome P450 enzymes in the brain: emerging evidence of biological significance. Trends Pharmacol. Sci. 32, 708-714. doi: 10.1016/j.tips.2011.08.005

Ferreira, P., Villanueva, R., Martínez-Júlvez, M., Herguedas, B., Marcuello, C., Fernandez-Silva, P., et al. (2014). Structural insights into the coenzyme mediated monomer-dimer transition of the pro-apoptotic apoptosis inducing factor. Biochemistry 53, 4204-4215. doi: 10.1021/bi500343r

Fierro, A., Osorio-Olivares, M., Cassels, B. K., Edmondson, D. E., SepulvedaBoza, S., and Reyes-Parada, M. (2007). Human and rat monoamine oxidase-A are differentially inhibited by (S).-4-alkylthioamphetamine derivatives: insights from molecular modeling studies. Bioorg. Med. Chem. 15, 5198-5206. doi: 10.1016/j.bmc.2007.05.021

Finberg, J. P. M. (2014). Update on the pharmacology of selective inhibitors of MAO-A and MAO-B: focus on modulation of CNS monoamine neurotransmitter release. Pharmacol. Ther. 143, 133-152. doi: 10.1016/j. pharmthera.2014.02.010

Fischer, M., Horn, S., Belkacemi, A., Kojer, K., Petrungaro, C., Habich, M., et al. (2013). Protein import and oxidative folding in the mitochondrial intermembrane space of intact mammalian cells. Mol. Biol. Cell. 24, 2160-2170. doi: $10.1091 / \mathrm{mbc} . \mathrm{E} 12-12-0862$

Fischer, T. D., Hylin, M. J., Zhao, J., Moore, A. N., Waxham, M. N., and Dash, P. K. (2016). Altered Mitochondrial Dynamics and TBI Pathophysiology. Front. Syst. Neurosci. 30, 10:29. doi: 10.3389/fnsys.2016.00029

Fowler, J. S., Logan, J., Shumay, E., Alia-Klein, N., Wang, G. J., and Volkow, N. D. (2015). Monoamine oxidase: radiotracer chemistry and human studies. J. Label. Compd. Radiopharm. 58, 51-64. doi: 10.1002/jlcr.3247

Frezza, C., Cipolat, S., Martins de Brito, O., Micaroni, M., Beznoussenko, G. V., Rudka, T., et al. (2006). OPA1 controls apoptotic cristae remodeling independently from mitochondrial fusion. Cell 126, 177-189. doi: 10.1016/j.cell.2006.06.025

Gallardo-Pujol, D., Andrés-Pueyo, A., and Maydeu-Olivares, A. (2013). MAOA genotype, social exclusion and aggression: an experimental test of a geneenvironment interaction. Genes Brain Behav. 12, 140-145. doi: 10.1111/j.1601183X.2012.00868.x

Galloway, C. A., Lee, H., Brookes, P. S., and Yoon, Y. (2014). Decreasing mitochondrial fission alleviates hepatic steatosis in a murine model of nonalcoholic fatty liver disease. Am. J. Physiol. Gastrointest. Liver. Physiol. 307, G632-G641. doi: 10.1152/ajpgi.00182.2014

Galloway, C. A., Lee, H., and Yoon, Y. (2012). Mitochondrial morphologyemerging role in bioenergetics. Free Radic. Biol. Med. 53, 2218-2228. doi: 10.1016/j.freeradbiomed.2012.09.035

Gardner, R. C., Burke, J. F., Nettiksimmons, J., Goldman, S., Tanner, C. M., and Yaffe, K. (2015). Traumatic brain injury in later life increases risk for Parkinson Disease. Ann. Neurol. 77, 987-995. doi: 10.1002/ana.24396

Gascon, E., and Gao, F. B. (2012). Cause or effect: misregulation of microRNA pathways in neurodegeneration. Front Neurosci. 6:48. doi: 10.3389/fnins.2012. 00048

Gáspárová, Z., Janega, P., Babal, P., Snirc, V., Stolc, S., Mach, M., et al. (2009). Effect of the new pyridoindole antioxidant SMe1EC2 on functional deficits and oedema formation in rat hippocampus exposed to ischaemia in vitro. Neuro Endocrinol. Lett. 30, 574-581.

Gáspárová, Z., Ondrejicková, O., Gajdošíková, A., Gajdošík, A., Snirc, V., and Stolc, S. (2010). Oxidative stress induced by the Fe2+/ascorbic acid system or model ischemia in vitro: effect of carvedilol and pyridoindole antioxidant SMe1EC2 in young and adult rat brain tissue. Interdiscipl. Toxicol. 3, 122-126. doi: $10.2478 / \mathrm{v} 10102-010-0051-\mathrm{x}$
Geldenhuys, W. J., Youdim, M. B. H., Carroll, R. T., and Van der Schyf, C. J. (2011) The emergence of designed multiple ligands for neurodegenerative disorders. Progr. Neurobiol. 94, 347-359. doi: 10.1016/j.pneurobio.2011.04.010

Ghezzi, D., Sevrioukova, I., Invernizzi, F., Lamperti, C., Mora, M., D’Adamo, P., et al. (2010). Severe X-linked mitochondrial encephalomyopathy associated with a mutation in apoptosis-inducing factor. Am. J. Hum. Genet. 86, 639-649. doi: 10.1016/j.ajhg.2010.03.002

Gillman, P. K. (2011). Advances pertaining to the pharmacology and interactions of irreversible nonselective monoamine oxidase inhibitors. $J$. Clin. Psychopharmacol. 31, 66-74. doi: 10.1097/JCP.0b013e31820469ea

Goedert, M. (2015). NEURODEGENERATION. Alzheimer's and Parkinson's diseases: the prion concept in relation to assembled A beta, tau, and alphasynuclein. Science 349:1255555. doi: 10.1126/science.1255555

Goldberg, R. N., Kishore, N., and Lennen, R. M. (2002). Thermodinamic quantities for the ionization reactions of buffers. J. Phys. Chem. Ref. Data 31, 231-370. doi: $10.1063 / 1.1416902$

Greig, N. H., Lahiri, D. K., and Sambamurti, K. (2002). Butyrylcholinesterase: an important new target in Alzheimer's disease therapy. Int. Psychogeriatr. 14, 77-91. doi: 10.1017/S1041610203008676

Griparic, L., Kanazawa, T., and van der Bliek, A. M. (2007). Regulation of the mitochondrial dynamin-like protein Opal by proteolytic cleavage. J. Cell Biol. 178, 757-764. doi: 10.1083/jcb.200704112

Griparic, L., van der Wel, N. N., Orozco, I. J., Peters, P. J., and van der Bliek, A. M. (2004). Loss of the intermembrane space protein Mgm1/OPA1 induces swelling and localized constrictions along the lengths of mitochondria. J. Biol. Chem. 279, 18792-18798. doi: 10.1074/jbc.M400920200

Guzior, N., Wieckowska, A., Panek, D., and Malawska, B. (2015). Recent Development of multifunctional agents as potential drug candidates for the treatment of Alzheimer's Disease. Curr. Med. Chem. 22, 373-404. doi: $10.2174 / 0929867321666141106122628$

Haddad, D., and Nakamura, K. (2015). Understanding the susceptibility of dopamine neurons to mitochondrial stressors in Parkinson's disease. FEBS Lett. 589(24 Pt A), 3702-3713. doi: 10.1016/j.febslet.2015.10.021

Hales, K. G. (2004). The machinery of mitochondrial fusion, division, and distribution, and emerging connections to apoptosis. Mitochondrion 4, 285-308. doi: 10.1016/j.mito.2004.05.007

Hales, K. G. (2010). Mitochondrial fusion and division. Nat. Educ. 3:12. Available online at: http://www.nature.com/scitable/topicpage/mitochondrialfusion-and-division- 14264007

Halling, J., Petersen, M. S., Grandjean, P., Weihe, P., and Brosen, K. (2008). Genetic predisposition to Parkinson's disease: CYP2D6 and HFE in the Faroe Islands. Pharmacogenet. Genomics 18, 209-212. doi: 10.1097/FPC.0b013e3282f5106e

Hangen, E., Féraud, O., Lachkar, S., Mou, H., Doti, N., Fimia, G. M., et al. (2015). Interaction between $\mathrm{AIF}$ and $\mathrm{CHCHD} 4$ regulates respiratory chain biogenesis. Mol. Cell 58, 1001-1014. doi: 10.1016/j.molcel.2015.04.020

He, D., Wu, H., Wei, Y., Liu, W., Huang, F., Shi, H., et al. (2015). Effects of harmine, an acetylcholinesterase inhibitor, on spatial learning and memory of APP/PS1 transgenic mice and scopolamine-induced memory impairment mice. Eur. J. Pharmac. 768, 96-107. doi: 10.1016/j.ejphar.2015.10.037

Hebda, M., Bajda, M., Wieckowska, A., Szalaj, N., Pasieka, A., Panek, D., et al. (2016). Synthesis, molecular modelling and biological evaluation of novel Heterodimeric, multiple ligands targeting Cholinesterases and Amyloid Beta. Molecules. 21, 24. doi: 10.3390/molecules21040410

Horáková, L., Sies, H., and Steenken, S. (1994). Antioxidant action of stobadine. Meth. Enzymol. 234, 572-580.

Horáková, L., and Stolc, S. (1998). Antioxidant and pharmacodynamic effects of pyridoindole stobadine. Gen. Pharmacol. 30, 627-638.

Hou, L. N., Xu, J. R., Zhao, Q. N., Gao, X. L., Cui, Y. Y., Xu, J., et al. (2014). A new motif in the N-terminal of acetylcholinesterase triggers amyloid- $\beta$ aggregation and deposition. CNS. Neurosci. Ther. 20, 59-66. doi: 10.1111/cns.12161

Hroch, L., Aitken, L., Benek, O., Dolezal, M., Kuca, K., Gunn-Moore, F., et al. (2015). Benzothiazoles - Scaffold of Interest for CNS Targeted Drugs. Curr. Med. Chem. 22, 730-747. doi: 10.2174/0929867322666141212120631

Hughes, R. E., Nikolic, K., and Ramsay, R. R. (2016). One for all? Hitting multiple Alzheimer's disease targets with one drug. Front. Neurosci. 10:177. doi: 10.3389/fnins.2016.00177

Inestrosa, N. C., Alvarez, A., Pérez, C. A., Moreno, R. D., Vicente, M., Linker, C., et al. (1996). Acetylcholinesterase accelerates assembly of 
amyloid-beta-peptides into Alzheimer's fibrils: possible role of the peripheral site of the enzyme. Neuron 16, 881-891. doi: 10.1016/S0896-6273(00)80108-7

Inestrosa, N. C., Dinamarca, M. C., and Alvarez, A. (2008). Amyloid-cholinesterase interactions - Implications for Alzheimer's disease. FEBS J. 275, 625-632. doi: 10.1111/j.1742-4658.2007.06238.x

Ingelman-Sundberg, M. (2004). Human drug metabolising cytochrome P450 enzymes: properties and polymorphisms. Naunyn Schmiedebergs Arch. Pharmacol. 369, 89-104. doi: 10.1007/s00210-003-0819-z

Ingelman-Sundberg, M., and Gomez, A. (2010). The past, present and future of pharmacoepigenomics. Pharmacogenomics 11, 625-627. doi: 10.2217/pgs.10.59

Ishihara, N., Fujita, Y., Oka, T., and Mihara, K. (2006). Regulation of mitochondrial morphology through proteolytic cleavage of OPA1. EMBO J. 25, 2966-2977. doi: 10.1038/sj.emboj.7601184

Ishimura, R., Martin, G. R., and Ackerman, S. L. (2008). Loss of apoptosisinducing factor results in cell-type-specific neurogenesis defects. J. Neurosci. 28, 4938-4948. doi: 10.1523/JNEUROSCI.0229-08.2008

Johri, A., and Beal, M. F. (2012). Mitochondrial dysfunction in neurodegenerative diseases. J. Pharamacol. Exp. Ther. 342 619-630. doi: 10.1124/jpet.112.192138

Joza, N., Oudit, G. Y., Brown, D., Bénit, P., Kassiri, Z., Vahsen, N., et al. (2005). Muscle-specific loss of apoptosis-inducing factor leads to mitochondrial dysfunction, skeletal muscle atrophy, and dilated cardiomyopathy. Mol. Cell. Biol. 25, 10261-10272. doi: 10.1128/MCB.25.23.10261-10272.2005

Juárez-Jiménez, J., Mendes, E., Galdeano, C., Martins, C., Silva, D. B., MarcoContelles, J., et al. (2014). Exploring the structural basis of the selective inhibition of monoamine oxidase A by dicarbonitrile aminoheterocycles: role of Asn181 and Ile335 validated by spectroscopic and computational studies. Biochim. Biophys. Acta 1844, 389-397. doi: 10.1016/j.bbapap.2013. 11.003

Juranek, I., Horakova, L., Rackova, L., and Stefek, M. (2010). Antioxidants in treating pathologies involving oxidative damage: an update on medicinal chemistry and biological activity of stobadine and related pyridoindoles. Curr. Med. Chem. 17, 552-570. doi: 10.2174/092986710790416317

Kaludercic, N., Carpi, A., Menabò, R., Di Lisa, F., and Paolocci, N. (2011). Monoamine oxidases (MAO). in the pathogenesis of heart failure and ischemia/reperfusion injury. Biochim. Biophys. Acta 1813, 1323-1332. doi: 10.1016/j.bbamcr.2010.09.010

Katritch, V., Cherezov, V., and Stevens, R. C. (2013). Structure-function of the G protein-coupled receptor superfamily. Annu. Rev. Pharmacol. Toxicol. 53, 531-556. doi: 10.1146/annurev-pharmtox-032112-135923

Kennedy, B. P., Ziegler, M. G., Alford, M., Hansen, L. A., Thal, L. J., and Masliah, E. (2003). Early and persistent alterations in prefrontal cortex MAO A and B in Alzheimer's disease. J. Neural. Transm. 110, 789-801.

Kettwig, M., Schubach, M., Zimmermann, F. A., Klinge, L., Mayr, J. A., Biskup, S., et al. (2015). From ventriculomegaly to severe muscular atrophy: expansion of the clinical spectrum related to mutations in AIFM1. Mitochondrion 21C, 12-18. doi: 10.1016/j.mito.2015.01.001

Kim, H., Sablin, S. O., and Ramsay, R. R. (1997). Inhibition of monoamine oxidase A by beta-carboline derivatives. Arch. Biochem. Biophys. 337, 137-142. doi: 10.1006/abbi.1996.9771

Kitz, R., and Wilson, I. B. (1962). Esters of methanesulfonic acid as irreversible inhibitors of acetylcholinesterase. J. Biol. Chem. 237, 3245-3249.

Klein, J. A., Longo-Guess, C. M., Rossmann, M. P., Seburn, K. L., Hurd, R. E., Frankel, W. N., et al. (2002). The harlequin mouse mutation downregulates apoptosis-inducing factor. Nature 419, 367-374. doi: 10.1038/nature01034

Koch, J. R., and Schmid, F. X. (2014). Mia40 targets cysteines in a hydrophobic environment to direct oxidative protein folding in the mitochondria. Nat. Commun. 5, 3041. doi: 10.1038/ncomms4041

Koshiba, T., Detmer, S. A., Kaiser, J. T., Chen, H., McCaffery, J. M., and Chan, D. C. (2004). Structural basis of mitochondrial tethering by mitofusin complexes. Science 305, 858-862. doi: 10.1126/science. 1099793

Krueger, M. J., Mazouz, F., Ramsay, R. R., Milcent, R., and Singer, T. P. (1995). Dramatic species differences in the susceptibility of Monoamine-Oxidase-B to a group of powerful inhibitors. Biochem. Biophys. Res. Commun. 206, 556-562. doi: 10.1006/bbrc.1995.1079

Kubo, M., Kishi, T., Matsunaga, S., and Iwata, N. (2015). Histamine H3 Receptor Antagonists for Alzheimer's Disease: a systematic review and meta-analysis of Randomized Placebo-controlled trials. J. Alzheimers Dis. 48, 667-671. doi: 10.3233/JAD-150393
Kupershmidt, L., Amit, T., Bar-Am, O., Youdim, M. B. H., and Weinreb, O. (2012). The novel multi-target iron chelating-radical scavenging compound M30 possesses beneficial effects on major hallmarks of Alzheimer's disease. Antiox. Redox Signal. 17, 860-877. doi: 10.1089/ars.2011.4279

Lecoutey, C., Hedou, D., Freret, T., Giannoni, P., Gaven, F., Since, M., et al. (2014). Design of donecopride, a dual serotonin subtype 4 receptor agonist/acetylcholinesterase inhibitor with potential interest for Alzheimer's disease treatment. Proc. Natl. Acad. Sci. U.S.A. 111, E3825-E3830. doi: $10.1073 /$ pnas. 1410315111

Lee, Y. J., Jeong, S. Y., Karbowski, M., Smith, C. L., and Youle, R. J. (2004). Roles of the mammalian mitochondrial fission and fusion mediators Fis1, Drp1, and Opal in apoptosis. Mol. Biol. Cell 15, 5001-5011. doi: 10.1091/mbc.E04-040294

Lenders, J. W. M., Eisenhofer, G., Abeling, N., Berger, W., Murphy, D. L., Konings, C. H., et al. (1996). Specific genetic deficiencies of the A and B isoenzymes of monoamine oxidase are characterized by distinct neurochemical and clinical phenotypes. J. Clin. Invest. 97, 1010-1019. doi: 10.1172/JCI118492

León, R., Garcia, A. G., and Marco-Contelles, J. (2013). Recent advances in the multitarget-directed ligands approach for the treatment of Alzheimer's disease. Med. Res. Rev. 33, 139-189. doi: 10.1002/med.20248

Lezi, E., and Swerdlow, R. H. (2012). Mitochondria in neurodegeneration. Adv. Exp. Med. Biol. 942, 269-286. doi: 10.1007/978-94-007-2869-1_12

Lezoualc'h, F. (2007). 5- $\mathrm{HT}_{4}$ receptor and Alzheimer's disease: the amyloid connection. Exp. Neurol. 205, 325-329. doi: 10.1016/j.expneurol.2007.02.001

Li, Y., Wang, P., Wei, J., Fan, R., Zuo, Y., Shi, M., et al. (2015). Inhibition of Drp1 by Mdivi-1 attenuates cerebral ischemic injury via inhibition of the mitochondriadependent apoptotic pathway after cardiac arrest. Neuroscience 311, 67-74. doi: 10.1016/j.neuroscience.2015.10.020

Liu, Y., Wang, Z., and Zhang, B. (2014). The relationship between monoamine oxidase B (MAOB). A644G polymorphism and Parkinson disease risk: a meta-analysis. Ann. Saudi Med. 34, 12-17. doi: 10.5144/0256-4947.2014.12

Lu, Y., Mo, C., Zeng, Z., Chen, S., Xie, Y., Peng, Q., et al. (2013). CYP2D6*4 allele polymorphism increases the risk of Parkinson's disease: evidence from meta-analysis. PLoS ONE 8:e84413. doi: 10.1371/journal.pone.0084413

Ludwig, E., Schmid, J., Beschke, K., and Ebner, T. (1999). Activation of human cytochrome P-450 3A4-catalyzed meloxicam 5'-methylhydroxylation by quinidine and hydroquinidine in vitro. J. Pharmacol. Exp. Ther. 290, 1-8.

Lum, C. T., and Stahl, S. M. (2012). Opportunities for reversible inhibitors of monoamine oxidase-A (RIMAs). in the treatment of depression. CNS Spectr. 17, 107-120. doi: 10.1017/S1092852912000594

Luo, Z., Sheng, J., Sun, Y., Lu, C., Yan, J., Liu, A., et al. (2013). Synthesis and evaluation of multi-target-directed ligands against Alzheimer's Disease based on the fusion of Donepezil and Ebselen. J. Med. Chem. 56, 9089-9099. doi: $10.1021 / \mathrm{jm} 401047 \mathrm{q}$

Lustbader, J. W., Cirilli, M., Lin, C., Xu, H. W., Takuma, K., Wang, N., et al. (2004). ABAD directly links A beta to mitochondrial toxicity in Alzheimer's disease. Science 304, 448-452. doi: 10.1126/science. 1091230

Majekova, M., Stecoza, C. E., Kovacikova, L., and Majek, P. (2013). "The use DRAGON molecular descriptors for the estimation of pharmacologic profile of dibenzothiepine and pyridoindole compounds," in Pokroky v analytickej chémii, eds S. Hrouzkova and J. Labuda (Bratislava: STU FCHPT), 504-520.

Malcomson, T., Yelekci, K., Borrello, M. T., Ganesan, A., Semina, E., De Kimpe, N., et al. (2015). cis-cyclopropylamines as mechanism-based inhibitors of monoamine oxidases. FEBS. J. 282, 3190-3198. doi: 10.1111/febs. 13260

Mandemakers, W., Morais, V. A., and De Strooper, B. (2007). A cell biological perspective on mitochondrial dysfunction in Parkinson disease and other neurodegenerative diseases. J. Cell. Sci. 120, 1707-1716. doi: 10.1242/jcs.03443

Marco-Contelles, J., Unzeta, M., Esteban, G., Ramsay, R., Romero, A., Martínez-Murillo, R., et al. (2016). ASS234, as a new multi-target directed Propargylamine for Alzheimer's Disease therapy. Front. Neurosci. 10:294. doi: 10.3389/fnins.2016.00294

McDonald, A. G., and Tipton, K. F. (2012). Enzymes: Irreversible Inhibition. eLS. doi: 10.1002/9780470015902.a0000601.pub2. Available online at: http:// olabout.wiley.com/WileyCDA/Section/id-390001.html

McDonald, G. R., Olivieri, A., Ramsay, R. R., and Holt, A. (2010). On the formation and nature of the imidazoline I(2). binding site on human monoamine oxidaseB. Pharmacol. Res. 62, 475-488. doi: 10.1016/j.phrs.2010.09.001 
Meadowcroft, M. D., Connor, J. R., Smith, M. B., and Yang, Q. X. (2009). MRI and histological analysis of beta-amyloid plaques in both human Alzheimer's disease and APP/PS1 transgenic mice. J. Magn. Reson. Imaging 29, 997-1007. doi: 10.1002/jmri.21731

Melancon, B. J., Tarr, J. C., Panarese, J. D., Wood, M. R., and Lindsley, C. W. (2013). Allosteric modulation of the M1 muscarinic acetylcholine receptor: improving cognition and a potential treatment for schizophrenia and Alzheimer's disease. Drug Discov. Today 18, 1185-1199. doi: 10.1016/j.drudis.2013.09.005

Mesulam, M. M., Guillozet, A., Shaw, P., Levey, A., Duysen, E. G., and Lockridge, O. (2002). Acetylcholinesterase knockouts establish central cholinergic pathways and can use butyrylcholinesterase to hydrolyze acetylcholine. Neuroscience 110, 627-639. doi: 10.1016/S0306-4522(01)00613-3

Meyer, J. H., Ginovart, N., Boovariwala, A., Sagrati, S., Hussey, D., Garcia, A., et al. (2006). Elevated monoamine oxidase A levels in the brain - An explanation for the monoamine imbalance of major depression. Arch. Gen. Psychiatry 63, 1209-1216. doi: 10.1001/archpsyc.63.11.1209

Meyer, K., Buettner, S., Ghezzi, D., Zeviani, M., Bano, D., and Nicotera, P. (2015). Loss of apoptosis-inducing factor critically affects MIA40 function. Cell. Death. Dis. 6:e1814. doi: 10.1038/cddis.2015.170

Mézešová, L., Jendruchová-Javorková, V., Vlkovicová, J., Kyselova, Z., Navarová, J., Bezek, S. et al. (2012). Antioxidant SMe1EC2 may attenuate the disbalance of sodium homeostasis in the organism induced by higher intake of cholesterol. Mol. Cell. Biochem. 366, 41-48. doi: 10.1007/s11010-012-1281-3

Miksys, S., and Tyndale, R. F. (2009). Brain drug-metabolizing cytochrome $\mathrm{P} 450$ enzymes are active in vivo, demonstrated by mechanism-based enzyme inhibition. Neuropsychopharmacology 34, 634-640. doi: 10.1038/npp.2008.110

Miksys, S., and Tyndale, R. F. (2013). Cytochrome P450-mediated drug metabolism in the brain. J. Psychiatry Neurosci. 38, 152-163. doi: 10.1503/jpn.1 20133

Milczek, E. M., Binda, C., Rovida, S., Mattevi, A., and Edmondson, D. E. (2011). 3zyx: Crystal Structure of Human Monoamine Oxidase $b$ in Complex with Methylene Blue and Bearing the Double Mutation i199a-y326a. Protein Data Bank. Available online at: https://www.ebi.ac.uk/pdbe/entry/pdb/3zyx/biology doi: $10.2210 / \mathrm{pdb} 3 z y x / \mathrm{pdb}$

Miramar, M. D., Costantini, P., Ravagnan, L., Saraiva, L. M., Haouzi, D., Brothers, G., et al. (2001). NADH oxidase activity of mitochondrial apoptosis-inducing factor. J. Biol. Chem. 276, 16391-16398. doi: 10.1074/jbc.M010498200

Moreira, P. I., Carvalho, C., Zhu, X., Smith, M. A., and Perry, G. (2010). Mitochondrial dysfunction is a trigger of Alzheimer's disease pathophysiology. Biochim. Biophys. Acta 1802, 2-10. doi: 10.1016/j.bbadis.2009.10.006

Morris, J. K., Bomhoff, G. L., Stanford, J. A., and Geiger, P. C. (2010). Neurodegeneration in an animal model of Parkinson's disease is exacerbated by a high-fat diet. Am. J. Physiol. Regul. Integr. Comp. Phys. 299, R1082-R1090. doi: 10.1152/ajpregu.00449.2010

Morrison, J. F. (1969). Kinetics of reversible inhibition of enzyme-catalysed reactions by tight-binding inhibitors. Biochim. Biophys. Acta 185, 269-286. doi: 10.1016/0005-2744(69)90420-3

Moussaud, S., Jones, D. R., Moussaud-Lamodière, E. L., Delenclos, M., Ross, O. A., and McLean, P. J. (2014). Alpha-synuclein and tau: teammates in neurodegeneration? Mol. Neurodegener. 9:43. doi: 10.1186/1750-1326-9-43

Murphy, M. P. (2009). How mitochondria produce reactive oxygen species. Biochem. J. 417, 1-13. doi: 10.1042/BJ20081386

Nakamura, K., Nemani, V. M., Azarbal, F., Skibinski, G., Levy, J. M., Egami, K., et al. (2011). Direct membrane association drives mitochondrial fission by the Parkinson disease-associated protein alpha-synuclein. J. Biol. Chem. 286, 20710-20726. doi: 10.1074/jbc.M110.213538

Naoi, M., and Maruyama, W. (2010). Monoamine Oxidase inhibitors as neuroprotective agents in age-dependent neurodegenerative disorders. Curr. Pharm. Design. 16, 2799-2817. doi: 10.2174/138161210793176527

Naoi, M., Maruyama, W., Akao, Y., Yi, H., and Yamaoka, Y. (2006). Involvement of type A monoamine oxidase in neurodegeneration: regulation of mitochondrial signaling leading to cell death or neuroprotection. J. Neural Transm. Suppl. 71, 67-77. doi: 10.1007/978-3-211-33328-0_8

Naoi, M., Maruyama, W., Yi, H., Akao, Y., Yamaoka, Y., and ShamotoNagai, M. (2007). Neuroprotection by propargylamines in Parkinson's disease: intracellular mechanism underlying the anti-apoptotic function and search for clinical markers. J. Neural Transm. Suppl. 72, 121-131. doi: 10.1007/978-3-21173574-9_15
Nebert, D. W., Wikvall, K., and Miller, W. L. (2013). Human cytochromes P450 in health and disease. Philos. Trans. R. Soc. Lond. Biol. Sci. 368:20120431. doi: 10.1098/rstb.2012.0431

Nicolet, Y., Lockridge, O., Masson, P., Fontecilla-Camps, J. C., and Nachon, F. (2003). Crystal structure of human butyrylcholinesterase and of its complexes with substrate and products. J. Biol. Chem. 278, 41141-41147. doi: 10.1074/jbc.M210241200

Nikolic, K., Mavridis, L., Bautista-Aguilera, O. M., Marco-Contelles, J., Stark, H., do Carmo Carreiras, M., et al. (2015). Predicting targets of compounds against neurological diseases using cheminformatic methodology. J. Comput. Aided Mol. Des. 29, 183-198. doi: 10.1007/s10822-014-9816-1

Nikolic, K., Mavridis, L., Djikic, T., Vucicevic, J., Agbaba, D., Yelekci, K., et al. (2016). Drug design for CNS diseases: polypharmacological profiling of compounds using cheminformatic, 3D-QSAR and virtual screening methodologies. Front. Neurosci. 10:265. doi: 10.3389/fnins.2016.00265

Novaroli, L., Daina, A., Favre, E., Bravo, J., Carotti, A., Leonetti, F., et al. (2006). Impact of species-dependent differences on screening, design, and development of MAO B inhibitors. J. Med. Chem. 49, 6264-6272. doi: 10.1021/jm060441e

Nunnari, J., and Suomalainen, A. (2012). Mitochondria: in sickness and in health Cell 148, 1145-1159. doi: 10.1016/j.cell.2012.02.035

Oesch-Bartlomowicz, B., and Oesch, F. (2005). Phosphorylation of cytochromes P450: first discovery of a posttranslational modification of a drugmetabolizing enzyme. Biochem. Biophys. Res. Commun. 338, 446-449. doi: 10.1016/j.bbrc.2005.08.092

Olanow, C. W., and Tatton, W. G. (1999). Ethiology and pathogenesis of Parkinson's disease. Ann. Rev. Neurosci. 22, 123-144. doi: 10.1146/annurev. neuro.22.1.123

Ooi, J., Hayden, M. R., and Pouladi, M. A. (2015). Inhibition of excessive monoamine oxidase $\mathrm{A} / \mathrm{B}$ activity protects against stress-induced neuronal death in Huntington Disease. Mol. Neurobiol. 52, 1850-1861. doi: 10.1007/s12035-014-8974-4

Pan, Y. Z., Gao, W., and Yu, A. M. (2009). MicroRNAs regulate CYP3A4 expression via direct and indirect targeting. Drug Metab. Dispos. 37, 2112-2117. doi: $10.1124 / \mathrm{dmd} .109 .027680$

Patil, P. O., Bari, S. B., Firke, S. D., Deshmukh, P. K., Donda, S. T., and Patil, D. A. (2013). A comprehensive review on synthesis and designing aspects of coumarin derivatives as monoamine oxidase inhibitors for depression and Alzheimer's disease. Bioorg. Med. Chem. 21, 2434-2450. doi: 10.1016/j.bmc.2013.02.017

Payami, H., Lee, N., Zareparsi, S., Gonzales McNeal, M., Camicioli, R., Bird, T. D., et al. (2001). Parkinson's disease, CYP2D6 polymorphism, and age. Neurology 56, 1363-1370. doi: 10.1212/WNL.56.10.1363

Perier, C., Bové, J., Dehay, B., Jackson-Lewis, V., Rabinovitch, P. S., Przedborski, S., et al. (2010). Apoptosis-inducing factor deficiency sensitizes dopaminergic neurons to parkinsonian neurotoxins. Ann. Neurol. 68, 184-192. doi: 10.1002/ana.22034

Perier, C., Bové, J., and Vila, M. (2012). Mitochondria and programmed cell death in Parkinson's disease: apoptosis and beyond. Antiox. Redox Signal. 16, 883-895. doi: 10.1089/ars.2011.4074

Perier, C., and Vila, M. (2012). Mitochondrial biology and Parkinson's disease. Cold Spring Harb. Perspect. Med. 2:a009332. doi: 10.1101/cshperspect.a009332

Persad, A. S., Stedeford, T., Tanaka, S., Chen, L., and Banasik, M. (2003). Parkinson's disease and CYP2D6 polymorphism in Asian populations: a metaanalysis. Neuroepidemiology 22, 357-361. doi: 10.1159/000072926

Petit, P. X., Susin, S. A., Zamzami, N., Mignotte, B., and Kroemer, G. (1996). Mitochondria and programmed cell death: back to the future. FEBS Lett. 396, 7-13. doi: 10.1016/0014-5793(96)00988-X

Piazzi, L., Cavalli, A., Colizzi, F., Belluti, F., Bartolini, M., Mancini, F., et al. (2008). Multi-target-directed coumarin derivatives: hAChE and BACE1 inhibitors as potential anti-Alzheimer compounds. Bioorg. Med. Chem. Lett. 18, 423-426. doi: 10.1016/j.bmcl.2007.09.100

Pisani, L., Catto, M., Leonetti, F., Nicolotti, O., Stefanachi, A., Campagna, F., et al. (2011). Targeting monoamine oxidases with multipotent ligands: an emerging strategy in the search of new drugs against neurodegenerative diseases. Curr. Med. Chem. 18, 4568-4587. doi: 10.2174/092986711797379302

Pisani, L., Farina, R., Soto-Otero, R., Denora, N., Mangiatordi, G. F., Nicolotti, O., et al. (2016). Searching for multi-targeting neurotherapeutics against 
Alzheimer's: discovery of potent AChE-MAO B inhibitors through the decoration of the 2H-Chromen-2-one structural motif. Molecules 21:362. doi: 10.3390/molecules21030362

Preissner, S. C., Hoffmann, M. F., Preissner, R., Dunkel, M., Gewiess, A., and Preissner, S. (2013). Polymorphic cytochrome P450 enzymes (CYPs) and their role in personalized therapy. PLOS ONE 8:e82562. doi: 10.1371/journal.pone. 0082562

Račková, L., Cumaoǧlu, A., Bağriacik, E. U., Štefek, M., Maechler, P., and Karasu, Ç. (2011). Novel hexahydropyridoindole derivative as prospective agent against oxidative damage in pancreatic $\beta$ cells. Med. Chem. 7, 711-717. doi: $10.2174 / 157340611797928370$

Rackova, L., Snirc, V., Jung, T., Stefek, M., Karasu, C., and Grune, T. (2009). Metabolism-induced oxidative stress is a mediator of glucose toxicity in HT22 neuronal cells. Free. Radic. Res. 43, 876-886. doi: 10.1080/10715760903104374

Rackova, L., Snirc, V., Majekova, M., Majek, P., and Stefek, M. (2006). Free radical scavenging and antioxidant activities of substituted hexahydropyridoindoles. Quantitative structure-activity relationships. J. Med. Chem. 49, 2543-2548. doi: 10.1021/jm060041r

Ramsay, R. R., Dunford, C., and Gillman, P. K. (2007). Methylene blue and serotonin toxicity: inhibition of monoamine oxidase A (MAO A). confirms a theoretical prediction. Br. J. Pharmacol. 152, 946-951. doi: 10.1038/sj.bjp.0707430

Ramsay, R. R., Olivieri, A., and Holt, A. (2011). An improved approach to steadystate analysis of monoamine oxidases. J. Neural Transm. 118, 1003-1019. doi: 10.1007/s00702-011-0657-y

Rao, V. K., Carlson, E. A., and Yan, S. S. (2014). Mitochondrial permeability transition pore is a potential drug target for neurodegeneration. Biochim. Biophys. Acta 1842, 1267-1272. doi: 10.1016/j.bbadis.2013.09.003

Reyes, A. E., Perez, D. R., Alvarez, A., Garrido, J., Gentry, M. K., Doctor, B. P., et al. (1997). A monoclonal antibody against acetylcholinesterase inhibits the formation of amyloid fibrils induced by the enzyme. Biochem. Biophys. Res. Commun. 232, 652-655. doi: 10.1006/bbrc.1997.6357

Riddles, P. W., Blakeley, R. L., and Zerner, B. (1979). Ellman's reagent: 5,5'dithiobis(2-nitrobenzoic acid).-reexamination. Anal. Biochem. 94, 75-81. doi: 10.1016/0003-2697(79)90792-9

Riedl, A. G., Watts, P. M., Brown, C. T., and Jenner, P. (1999). P450 and heme oxygenase enzymes in the basal ganglia and their roles in Parkinson's disease. Adv. Neurol. 80, 271-286.

Rinaldi, C., Grunseich, C., Sevrioukova, I. F., Schindler, A., Horkayne-Szakaly, I., Lamperti, C., et al. (2012). Cowchock syndrome is associated with a mutation in apoptosis-inducing factor. Am. J. Hum. Genet. 91, 1095-1102. doi: 10.1016/j.ajhg.2012.10.008

Rintoul, G. L., and Reynolds, I. J. (2010). Mitochondrial trafficking and morphology in neuronal injury. Biochim Biophys Acta 1802, 143-150. doi: 10.1016/j.bbadis.2009.09.005

Rochais, C., Lecoutey, C., Gaven, F., Giannoni, P., Hamidouche, K., Hedou, D., et al. (2015). Novel multitarget-directed ligands (MTDLs) with acetylcholinesterase (AChE) inhibitory and serotonergic subtype 4 receptor (5-HT4R) agonist activities as potential agents against Alzheimer's disease: the design of donecopride. J. Med. Chem. 58, 3172-3187. doi: 10.1021/acs.jmedchem.5b00115

Russo, O., Cachard-Chastel, M., Riviere, C., Giner, M., Soulier, J. L., Berthouze, M., et al. (2009). Design, synthesis, and biological evaluation of New 5-HT(4). receptor agonists: application as amyloid cascade modulators and potential therapeutic utility in Alzheimer's Disease. J. Med. Chem. 52, 2214-2225. doi: $10.1021 /$ jm $801327 \mathrm{q}$

Sacher, J., Houle, S., Parkes, J., Rusjan, P., Sagrati, S., Wilson, A. A., et al. (2011). Monoamine oxidase A inhibitor occupancy during treatment of major depressive episodes with moclobemide or St. John's wort: an [C-11]-harmine PET study. J. Psychiatry Neurosci. 36, 375-382. doi: 10.1503/jpn.100117

Samadi, A., Chioua, M., Bolea, I., de Los Ríos, C., Iriepa, I., Moraleda, I., et al. (2011). Synthesis, biological assessment and molecular modeling of new multipotent MAO and cholinesterase inhibitors as potential drugs for the treatment of Alzheimer's disease. Eur. J. Med. Chem. 46, 4665-4678. doi: 10.1016/j.ejmech.2011.05.048

Samadi, A., Marco Contelles, J. L., Bolea Tomas, I., Luque Garriga, F. J., and Unzeta Lopez, M. (2015). Derivatives of Propargylamine having Neuroprotective Capacity for the Treatment of Alzheimer's and Parkinson's Diseases. Washington,
DC: Consejo Superior de Investigaciones Cientificas; Universitat Autonoma de Barcelona; Universidad de Barcelona, US20130012522 A1. U.S. Patent and Trademark Office.

Sankowski, R., Mader, S., and Valdés-Ferrer, S. I. (2015). Systemic inflammation and the brain: novel roles of genetic, molecular, and environmental cues as drivers of neurodegeneration. Front. Cell. Neurosci. 9:28. doi: 10.3389/fncel.2015.00028

Santana, L., Uriarte, E., González-Díaz, H., Zagotto, G., Soto-Otero, R., and Mendez-Alvarez, E. (2006). A QSAR model for in silico screening of MAOA inhibitors. Prediction, synthesis, and biological assay of novel coumarins. J. Med. Chem. 49, 1149-1156. doi: 10.1021/jm0509849

Saraste, A., and Pulkki, K. (2000). Morphologic and biochemical hallmarks of apoptosis. Cardiovasc. Res. 45, 528-537. doi: 10.1016/S0008-6363(99)00384-3

Schapira, A. H., and Gegg, M. (2011). Mitochondrial contribution to Parkinson's disease pathogenesis. Parkinsons Dis. 2011:159160. doi: 10.4061/2011/159160

Schipper, H. M. (2012). Neurodegeneration with brain iron accumulation Clinical syndromes and neuroimaging. Biochim Biophys. Acta 1822, 350-360. doi: 10.1016/j.bbadis.2011.06.016

Schmidt, D. M. Z., and McCafferty, D. G. (2007). trans-2-phenylcyclopropylamine is a mechanism-based inactivator of the histone demethylase LSD1. Biochemistry 46, 4408-4416. doi: 10.1021/bi0618621

Sedláčková, N., Ponechalová, V., Ujházy, E., Dubovický, M., and Mach, M. (2011). Anxiolytic activity of pyridoindole derivatives SMe1EC2 and SMe1M2: behavioral analysis using rat model. Interdiscip. Toxicol. 4, 211-215. doi: 10.2478/v10102-011-0032-8

Sevrioukova, I. F. (2009). Redox-linked conformational dynamics in apoptosisinducing factor. J. Mol. Biol. 390, 924-938. doi: 10.1016/j.jmb.2009.05.013

Sevrioukova, I. F. (2011). Apoptosis-inducing factor: structure, function, and redox regulation. Antioxid. Redox Signal. 14, 2545-2579. doi: 10.1089/ars.2010.3445

Shahabi, H. N., Andersson, D. R., and Nissbrandt, H. (2008). Cytochrome P450 $2 \mathrm{E} 1$ in the substantia nigra: relevance for dopaminergic neurotransmission and free radical production. Synapse 62, 379-388. doi: 10.1002/syn.20505

Sharma, U., Roberts, E. S., and Hollenberg, P. F. (1996). Inactivation of cytochrome P4502B1 by the monoamine oxidase inhibitors R-(-).-deprenyl and clorgyline. Drug Metab. Dispos. 24, 669-675.

Shelke, S. M., Bhosale, S. H., Dash, R. C., Suryawanshi, M. R., and Mahadik, K. R. (2011). Exploration of new scaffolds as potential MAO-A inhibitors using pharmacophore and 3D-QSAR based in silico screening. Bioorg. Med. Chem. Lett. 21, 2419-2424. doi: 10.1016/j.bmcl.2011.02.072

Sheng, Z. H. (2014). Mitochondrial trafficking and anchoring in neurons: New insight and implications. J. Cell Biol. 204, 1087-1098. doi: $10.1083 /$ jcb. 201312123

Sheng, Z. H., and Cai, Q. (2012). Mitochondrial transport in neurons: impact on synaptic homeostasis and neurodegeneration. Nat. Rev. Neurosci. 13, 77-93. doi: $10.1038 / \mathrm{nrn} 3156$

Shih, J. C., and Chen, K. (1999). MAO-A and -B gene knock-out mice exhibit distinctly different behavior. Neurobiology (Bp). 7, 235-246.

Silverman, R. B. (1983). Mechanism of inactivation of monoamine-oxidase by trans-2-phenylcyclopropylamine and the structure of the enzyme-inactivator adduct. J. Biol. Chem. 258, 4766-4769.

Simone, V., Pessina, F., Durante, M., Frosini, M., Marco-Contelles, J., Unzeta, M., et al. (2014). Interaction of Novel Monoamino Oxidase Inhibitor with Cytochrome P450, Xjenza online, 94. Available online at: www.xjenza.org

Singh, N. K., Banerjee, B. D., Bala, K., Basu, M., and Chhillar, N. (2014). Polymorphism in cytochrome P450 2D6, Glutathione S-Transferases Pi 1 genes, and organochlorine pesticides in Alzheimer Disease: a case-control study in North Indian Population. J. Geriatr. Psychiatry Neurol. 27, 119-127. doi: 10.1177/0891988714522698

Sipes, N. S., Martin, M. T., Kothiya, P., Reif, D. M., Judson, R. S., Richard, A. M., et al. (2013). Profiling 976 ToxCast chemicals across 331 enzymatic and receptor signaling assays. Chem. Res. Toxicol. 26, 878-895. doi: 10.1021/tx400021f

Smutny, T., Mani, S., and Pavek, P. (2013). Post-translational and posttranscriptional modifications of pregnane $\mathrm{X}$ receptor (PXR) in regulation of the cytochrome P450 superfamily. Curr. Drug Metab. 14, 1059-1069. doi: 10.2174/1389200214666131211153307

Sorrentino, L., Calogero, A. M., Pandini, V., Vanoni, M. A., Sevrioukova, I. F., and Aliverti, A. (2015). Key role of the adenylate moiety and 
integrity of the Adenylate-Binding Site for the $\mathrm{NAD}(+) / \mathrm{H}$ Binding to mitochondrial apoptosis-inducing factor. Biochemistry 54, 6996-7009. doi: 10.1021/acs.biochem.5b00898

Sotníková, R., Nedelčevová, J., Navarová, J., Nosálová, V., Drábiková, K., Szöcs, K., et al. (2011). Protection of the vascular endothelium in experimental situations. Interdiscip. Toxicol. 4, 20-26. doi: 10.2478/v10102-011-0005-y

Sridar, C., Kenaan, C., and Hollenberg, P. F. (2012). Inhibition of bupropion metabolism by selegiline: mechanism-based inactivation of human CYP2B6 and characterization of glutathione and peptide adducts. Drug Metab. Dispos. 40, 2256-2266. doi: 10.1124/dmd.112.046979

Stefek, M., Milackova, I., Juskova Karasova, M., and Snirc, V. (2013). Antioxidant action of the hexahydropyridoindole SMe1EC2 in the cellular system of isolated red blood cells in vitro. Redox Rep. 18, 71-75. doi: 10.1179/1351000213Y.0000000043

Stolc, S., Povazanec, F., Bauer, V., Majekova, M., Wilcox, A. L., Snirc, V., et al. (2010). Pyridoindole Derivatives with Antioxidant Properties: Synthesis, Therapy and Pharmaceutical Remedies. P 287506. Slovak Republic: Slovak Patent Agency.

Stolc, S., Snirc, V., Gajdosikova, A., Gajdosik, A., Gsparova, Z., Ondrejickova, O., et al. (2011). "Pyridoindoles with antioxidant and neuroprotective actions: a review," in New frontiers in Molecular Mechanisms in Neurological and Psychiatric Disorders, Vol. 1, eds E. Babušíková, D. Dobrota, and J. Lehotský (Martin: JLF UK-Ústav lekárskej biochémie), 316-341. ISBN: 978-8088866-99-2.

Stolc, S., Snirc, V., Majekova, M., Gáspárová, Z., Gajdosíková, A., and Stvrtina, S. (2006). Development of the new group of indole-derived neuroprotective drugs affecting oxidative stress. Cell. Mol. Neurobiol. 26, 1495-1504. doi: 10.1007/s10571-006-9037-9

Strano-Rossi, S., Anzillotti, L., Dragoni, S., Pellegrino, R. M., Goracci, L., Pascali, V. L., et al. (2014). Metabolism of JWH-015, JWH-098, JWH-251, and JWH-307 in silico and in vitro: a pilot study for the detection of unknown synthetic cannabinoids metabolites. Anal. Bioanal. Chem. 406, 3621-3636. doi: 10.1007/s00216-014-7793-9

Sun, Q., Peng, D. Y., Yang, S. G., Zhu, X. L., Yang, W. C., and Yang, G. F. (2014). Syntheses of coumarin-tacrine hybrids as dual-site acetylcholinesterase inhibitors and their activity against butylcholinesterase, A-beta aggregation, and beta-secretase. Bioorg. Med. Chem. 22, 4784-4791. doi: 10.1016/j.bmc.2014.06.057

Susin, S. A., Lorenzo, H. K., Zamzami, N., Marzo, I., Snow, B. E., Brothers, G. M., et al. (1999). Molecular characterization of mitochondrial apoptosis-inducing factor. Nature 397, 441-446. doi: 10.1038/17135

Swomley, A. M., and Butterfield, D. A. (2015). Oxidative stress in Alzheimer disease and mild cognitive impairment: evidence from human data provided by redox proteomics. Arch. Toxicol. 89, 1669-1680. doi: 10.1007/s00204-0151556-z

Sziráki, I., Kardos, V., Patthy, M., Pátfalusi, M., Gaál, J., Solti, M., et al. (1994). Amphetamine-metabolites of deprenyl involved in protection against neurotoxicity induced by MPTP and 2'-methyl-MPTP. J. Neural. Transm. 41, 207-219. doi: 10.1007/978-3-7091-9324-2_27

Talati, R., Reinhart, K., Baker, W., White, C. M., and Coleman, C. I. (2009). Pharmacologic treatment of advanced Parkinson's disease: a meta-analysis of COMT inhibitors and MAO-B inhibitors. Parkinsonism Relat. Disord. 15, 500-505. doi: 10.1016/j.parkreldis.2008.12.007

Thal, D. M., Sun, B., Feng, D., Nawaratne, V., Leach, K., Felder, C. C., et al. (2016). Crystal structures of the M1 and M4 muscarinic acetylcholine receptors. Nature 531, 335-340. doi: 10.1038/nature17188

Tsuchiya, Y., Nakajima, M., Takagi, S., Taniya, T., and Yokoi, T. (2006). MicroRNA regulates the expression of human cytochrome P450 1B1. Cancer Res. 66, 9090-9098. doi: 10.1158/0008-5472.CAN-06-1403

Ujhazy, E., Dubovicky, M., Ponechalova, V., Navarova, J., Brucknerova, I., Snirc, V., et al. (2008). Prenatal developmental toxicity study of the pyridoindole antioxidant SMe1EC2 in rats. Neuro Endocrinol. Lett. 29, 639-643.

Unzeta, M., Esteban, G., Bolea, I., Fogel, W. A., Ramsay, R. R., Youdim, M. B., et al. (2016). Multi-target directed donepezil-like ligands for Alzheimer's disease. Front. Neurosci. 10:205. doi: 10.3389/fnins.2016.00205

Upadhyay, A. K., Wang, J., and Edmondson, D. E. (2008). Comparison of the structural properties of the active site cavities of human and rat monoamine oxidase A and B in their soluble and membrane-bound forms. Biochemistry 47, 526-536. doi: 10.1021/bi7019707

Urbano, A., Lakshmanan, U., Choo, P. H., Kwan, J. C., Ng, P. Y., Guo, K., et al. (2005). AIF suppresses chemical stress-induced apoptosis and maintains the transformed state of tumor cells. EMBO J. 24, 2815-2826. doi: 10.1038/sj.emboj.7600746

Uttara, B., Singh, A. V., Zamboni, P., and Mahajan, R. T. (2009). Oxidative stress and neurodegenerative diseases: a review of upstream and downstream antioxidant therapeutic options. Curr. Neuropharmacol. 7, 65-74. doi: 10.2174/157015909787602823

Vaglini, F., Viaggi, C., Piro, V., Pardini, C., Gerace, C., Scarselli, M., et al. (2013). Acetaldehyde and parkinsonism: role of CYP450 2E1. Front. Behav. Neurosci. 7:71. doi: 10.3389/fnbeh.2013.00071

Vahsen, N., Candé, C., Briere, J. J., Benit, P., Joza, N., Larochette, N., et al. (2004). AIF deficiency compromises oxidative phosphorylation. EMBO J. 23, 4679-4689. doi: 10.1038/sj.emboj.7600461

Valaasani, K. R., Sun, Q., Hu, G., Li, J., Du, F., Guo, Y., et al. (2014). Identification of human $\mathrm{ABAD}$ inhibitors for rescuing A-beta-mediated mitochondrial dysfunction. Curr. Alzheimer Res. 11, 128-136. doi: 10.2174/1567205011666140130150108

van Empel, V. P., Bertrand, A. T., van der Nagel, R., Kostin, S., Doevendans, P. A., Crijns, H. J., et al. (2005). Downregulation of apoptosis-inducing factor in harlequin mutant mice sensitizes the myocardium to oxidative stressrelated cell death and pressure overload-induced decompensation. Circ. Res. 96, e92-e101. doi: 10.1161/01.res.0000172081.30327.28

van Unen, J., Woolard, J., Rinken, A., Hoffmann, C., Hill, S. J., Goedhart, J., et al. (2015). A perspective on studying G-Protein-Coupled receptor signaling with resonance energy transfer biosensors in living organisms. Mol. Pharmacol. 88, 589-595. doi: 10.1124/mol.115.098897

Vilar, R., Coelho, H., Rodrigues, E., Gama, M. J., Rivera, I., Taioli, E., et al. (2007). Association of A313 G polymorphism (GSTP1*B) in the glutathioneS-transferase P1 gene with sporadic Parkinson's disease. Eur. J. Neurol. 14, 156-161. doi: 10.1111/j.1468-1331.2006.01590.x

Vilar, S., Ferino, G., Quezada, E., Santana, L., and Friedman, C. (2012). Predicting monoamine oxidase inhibitory activity through ligand-based models. Curr. Top. Med. Chem. 12, 2258-2274. doi: 10.2174/1568026128052 19987

Villanueva, R., Ferreira, P., Marcuello, C., Usón, A., Miramar, M. D., Peleato, M. L., et al. (2015). Key residues regulating the reductase activity of the human mitochondrial apoptosis inducing factor. Biochemistry 54, 5175-5184. doi: 10.1021/acs.biochem.5b00696

Vohora, D, and Bhowmik, M. (2012). Histamine H3 receptor antagonists/inverse agonists on cognitive and motor processes: relevance to Alzheimer's disease, ADHD, schizophrenia, and drug abuse. Front. Syst. Neurosci. 6:72. doi: $10.3389 /$ fnsys.2012.00072

Waagepetersen, H. S., Sonnewald, U., and Schousboe, A. (2003). Compartmentation of glutamine, glutamate, and GABA metabolism in neurons and astrocytes: functional implications. Neuroscientist 9, 398-403. doi: $10.1177 / 1073858403254006$

Walsh, C. T. (2013). "Why enzymes as drug targets?" in Evaluation of Enzyme Inhibitors in Drug Discovery: A Guide for Medicinal Chemists and Pharmacologists," 2nd Edn., ed R. A. Copeland (Chichester: John Wiley \& Sons, Inc.), 1-23. doi: 10.1002/9781118540398

Walter, M., and Stark, H. (2012). Histamine receptor subtypes: a century of rational drug design. Front. Biosci. 1:279. doi: 10.2741/s279

Wang, C., and Youle, R. J. (2009). The role of mitochondria in apoptosis*. Annu. Rev. Genet. 43, 95-118. doi: 10.1146/annurev-genet-102108-134850

Wang, L., Esteban, G., Ojima, M., Bautista-Aguilera, O. M., Inokuchi, T., Moraleda, I., et al. (2014). Donepezil + propargylamine +8 -hydroxyquinoline hybrids as new multifunctional metal-chelators, ChE and MAO inhibitors for the potential treatment of Alzheimer's disease. Eur. J. Med. Chem. 80, 543-561. doi: 10.1016/j.ejmech.2014.04.078

Wang, X., Huang, T., Bu, G., and Xu, H. (2014). Dysregulation of protein trafficking in neurodegeneration. Mol. Neurodegener. 9:31. doi: 10.1186/17501326-9-31

Waxman, D. J. (1999). P450 gene induction by structurally diverse xenochemicals: central role of nuclear receptors CAR, PXR, and PPAR. Arch. Biochem. Biophys. 369, 11-23. doi: 10.1006/abbi.1999.1351 
Weichert, D., Stanek, M., Hübner, H., and Gmeiner, P. (2016). Structure-guided development of dual $\beta 2$ adrenergic/dopamine D2 receptor agonists. Bioorg. Med. Chem. 24, 2641-2653. doi: 10.1016/j.bmc.2016.04.028

Weinreb, O., Amit, T., Bar-Am, O., and Youdim, M. B. (2012). Ladostigil: a novel multimodal neuroprotective drug with cholinesterase and brainselective monoamine oxidase inhibitory activities for Alzheimer's disease treatment. Curr. Drug Targets 13, 483-494. doi: 10.2174/138945012799 499794

Weinreb, O., Amit, T., Bar-Am, O., and Youdim, M. B. (2016). Neuroprotective effects of multifaceted hybrid agents targeting MAO, cholinesterase, iron and $\beta$-amyloid in aging and Alzheimer's disease. Br. J. Pharmacol. 173, 2080-2094. doi: 10.1111/bph.13318

Weinreb, O., Amit, T., Riederer, P., Youdim, M. B. H., and Mandel, S. A. (2011). Neuroprotective profile of the multitarget drug rasagiline in Parkinson's disease. Int. Rev. Neurobiol. 100, 127-149. doi: 10.1016/B978-0-12-386467-3. 00007-8

Weinreb, O., Badinter, F., Amit, T., Bar-Am, O., and Youdim, M. B. (2015). Effect of long-term treatment with rasagiline on cognitive deficits and related molecular cascades in aged mice. Neurobiol. Aging 36, 2628-2636. doi: 10.1016/j.neurobiolaging.2015.05.009

Weissbach, H., Smith, T. E., Daly, J. W., Witkop, B., and Udenfriend, S. (1960). A rapid spectrophotometric assay of Monoamine Oxidase based on the rate of disappearance of kynuramine. J. Biol. Chem 235, 1160-1163.

Werlinder, V., Backlund, M., Zhukov, A., and Ingelman-Sundberg, M. (2001). Transcriptional and post-translational regulation of CYP1A1 by primaquine. J. Pharmacol. Exp. Ther. 297, 206-214.

Westermann, B. (2012). Bioenergetic role of mitochondrial fusion and fission. Biochim. Biophys. Acta 1817, 1833-1838. doi: 10.1016/j.bbabio.2012. 02.033

Witcher, K. G., Eiferman, D. S., and Godbout, J. P. (2015). Priming the Inflammatory Pump of the CNS after Traumatic Brain Injury. Trends Neurosci. 38, 609-620. doi: 10.1016/j.tins.2015.08.002

Witte, M. E., Mahad, D. J., Lassmann, H., and van Horssen, J. (2014). Mitochondrial dysfunction contributes to neurodegeneration in multiple sclerosis. Trends Mol. Med. 20, 179-187. doi: 10.1016/j.molmed.2013. 11.007

Woodard, C. M., Campos, B. A., Kuo, S. H., Nirenberg, M. J., Nestor, M. W., Zimmer, M., et al. (2014). iPSC-derived dopamine neurons reveal differences between monozygotic twins discordant for Parkinson's disease. Cell Reports. 9, 1173-1182. doi: 10.1016/j.celrep.2014.10.023

Xie, S. S., Lan, J. S., Wang, X., Wang, Z. M., Jiang, N., Li, F., et al. (2016). Design, synthesis and biological evaluation of novel donepezil-coumarin hybrids as multi-target agents for the treatment of Alzheimer's disease. Bioorg. Med. Chem. 24, 1528-1539. doi: 10.1016/j.bmc.2016.02.023

Xie, S. S., Wang, X., Jiang, N., Yu, W., Wang, K. D. G., Lan, J. S., et al. (2015). Multi-target tacrine-coumarin hybrids: cholinesterase and monoamine oxidase B inhibition properties against Alzheimer's disease. Eur. J. Med. Chem. 95, 153-165. doi: 10.1016/j.ejmech.2015.03.040

Xu, L., Ryu, J., Nguyen, J. V., Arena, J., Rha, E., Vranis, P., et al. (2015). Evidence for accelerated tauopathy in the retina of transgenic P301S tau mice exposed to repetitive mild traumatic brain injury. Exp. Neurol. 273, 168-176. doi: 10.1016/j.expneurol.2015.08.014

Yan, R., Fan, Q., Zhou, J., and Vassar, R. (2016). Inhibiting BACE1 to reverse synaptic dysfunctions in Alzheimer's disease. Neurosci. Biobehav. Rev. 65, 326-340. doi: 10.1016/j.neubiorev.2016.03.025
Yan, R., and Vassar, R. (2014). Targeting the beta secretase BACE1 for Alzheimer's disease therapy. Lancet Neurol. 13, 319-329. doi: 10.1016/S14744422(13)70276-X

Yang, S. Y., He, X. Y., Isaacs, C., Dobkin, C., Miller, D., and Philipp, M. (2014). Roles of 17 beta-hydroxysteroid dehydrogenase type 10 in neurodegenerative disorders. J. Steroid Biochem. Mol. Biol. 143, 460-472. doi: 10.1016/j.jsbmb.2014.07.001

Youdim, M. B. (2013). Multi target neuroprotective and neurorestorative anti-Parkinson and anti-Alzheimer drugs ladostigil and m30 derived from rasagiline. Exp. Neurobiol. 22, 1-10. doi: 10.5607/en.2013.22.1.1

Youdim, M. B. H., Edmondson, D., and Tipton, K. F. (2006). The therapeutic potential of monoamine oxidase inhibitors. Nat. Rev. Neurosci. 7, 295-309. doi: $10.1038 / \mathrm{nrn} 1883$

Youdim, M. B., and Oh, Y. J. (2013). Promise of neurorestoration and mitochondrial biogenesis in Parkinson's disease with multi target drugs: an alternative to stem cell therapy. Exp. Neurobiol. 22, 167-172. doi: 10.5607/en.2013.22.3.167

Youle, R. J., and van der Bliek, A. M. (2012). Mitochondrial fission, fusion, and stress. Science 337, 1062-1065. doi: 10.1126/science.1219855

Zanger, U. M., and Schwab, M. (2013). Cytochrome P450 enzymes in drug metabolism: regulation of gene expression, enzyme activities, and impact of genetic variation. Pharmacol. Ther. 138, 103-141. doi: 10.1016/j.pharmthera.20 12.12.007

Zanna, C., Ghelli, A., Porcelli, A. M., Karbowski, M., Youle, R. J., Schimpf, S., et al. (2008). OPAl mutations associated with dominant optic atrophy impair oxidative phosphorylation and mitochondrial fusion. Brain 131, 352-367. doi: 10.1093/brain/awm335

Zellner, M., Baureder, M., Rappold, E., Bugert, P., Kotzailias, N., Babeluk, R., et al. (2012). Comparative platelet proteome analysis reveals an increase of monoamine oxidase-B protein expression in Alzheimer's disease but not in non-demented Parkinson's disease patients. J. Proteomics 75, 2080-2092. doi: 10.1016/j.jprot.2012.01.014

Zhou, M. J., Diwu, Z. J., PanchukVoloshina, N., and Haugland, R. P. (1997). A stable nonfluorescent derivative of resorufin for the fluorometric determination of trace hydrogen peroxide: applications in detecting the activity of phagocyte NADPH oxidase and other oxidases. Anal. Biochem. 253, 162-168. doi: 10.1006/abio.1997.2391

Zhu, Y., Xiao, K., Ma, L., Xiong, B., Fu, Y., Yu, H., et al. (2009). Design, synthesis and biological evaluation of novel dual inhibitors of acetylcholinesterase and beta-secretase. Bioorg. Med. Chem. 17, 1600-1613. doi: 10.1016/j.bmc.2008. 12.067

Züchner, S., Mersiyanova, I. V., Muglia, M., Bissar-Tadmouri, N., Rochelle, J., Dadali, E. L., et al. (2004). Mutations in the mitochondrial GTPase mitofusin 2 cause Charcot-Marie-Tooth neuropathy type 2A. Nat. Genet. 36, 449-451. doi: $10.1038 /$ ng1341

Conflict of Interest Statement: The authors declare that the research was conducted in the absence of any commercial or financial relationships that could be construed as a potential conflict of interest.

Copyright (c) 2016 Ramsay, Majekova, Medina and Valoti. This is an open-access article distributed under the terms of the Creative Commons Attribution License (CC $B Y)$. The use, distribution or reproduction in other forums is permitted, provided the original author(s) or licensor are credited and that the original publication in this journal is cited, in accordance with accepted academic practice. No use, distribution or reproduction is permitted which does not comply with these terms. 